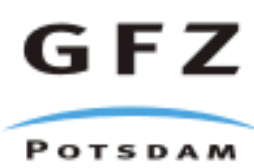

Originally published as:

Schmid, R., Steigenberger, P., Gendt, G., Ge, M., Rothacher, M. (2007): Generation of a consistent absolute phase center correction model for GPS receiver and satellite antennas. Journal of Geodesy, 81, 12,

DOI: 10.1007/s00190-007-0148-y. 


\author{
Ralf Schmid • Peter Steigenberger • Gerd Gendt • \\ Maorong Ge • Markus Rothacher
}

\title{
Generation of a Consistent Absolute Phase Center Correction Model for GPS Receiver and Satellite Antennas
}

\begin{abstract}
The development and values of the new absolute phase center correction model for global positioning system (GPS) receiver and satellite antennas as adopted by the International GNSS Service are presented. Fixing absolute receiver antenna phase center corrections to robot-based calibrations, the GeoForschungsZentrum Potsdam and the Technische Universität München reprocessed more than 10 years of GPS data in order to generate a consistent set of nadir-dependent phase center variations (PCVs) and offsets in $z$-direction pointing toward the Earth for all GPS satellites in orbit during that period. The agreement between the two solutions estimated by independent software packages is better than $1 \mathrm{~mm}$ for the PCVs and about $4 \mathrm{~cm}$ for the $z$-offsets. In addition, the long time series facilitates the study of correlations of the satellite antenna corrections with several other parameters such as the global terrestrial scale or the orientation of the orbital planes with respect to the Sun. Finally, completely reprocessed GPS solutions using different phase center correction models demonstrate the benefits from switching from relative to absolute antenna phase center corrections. For example, tropospheric zenith delay biases between GPS and very long baseline interferometry, as well as the drift of the terrestrial scale, are reduced and the orbit consistency is improved.
\end{abstract}

Keywords GPS · Satellite antenna · Receiver antenna · Absolute phase center corrections · GPS reprocessing

\footnotetext{
R. Schmid

Institut für Astronomische und Physikalische Geodäsie, Technische Universität München, Arcisstraße 21, 80333 München, Germany

Tel.: +49-89-28923193

Fax: +49-89-28923178

E-mail: schmid@bv.tum.de

P. Steigenberger

Forschungseinrichtung Satellitengeodäsie, Technische Universität München, Arcisstraße 21, 80333 München, Germany

E-mail: steigenberger@gfz-potsdam.de

Present address: GeoForschungsZentrum Potsdam, Telegrafenberg A17, 14473 Potsdam, Germany

G. Gendt

GeoForschungsZentrum Potsdam, Telegrafenberg A17, 14473 Potsdam, Germany

E-mail: gendt@gfz-potsdam.de

M. Ge

GeoForschungsZentrum Potsdam, Telegrafenberg A17, 14473 Potsdam, Germany

E-mail: maor@gfz-potsdam.de

M. Rothacher

GeoForschungsZentrum Potsdam, Telegrafenberg A17, 14473 Potsdam, Germany

E-mail: rothacher@gfz-potsdam.de
} 


\section{Introduction}

Starting 30 June 1996, relative global positioning system (GPS) antenna phase center corrections had been applied by most of the analysis centers (ACs) of the International GNSS Service (IGS; Dow et al. 2005) in order to allow for a non-spherical phase response of the tracking antennas. These corrections comprised mean offsets of the electrical antenna phase center compared to the physical antenna reference point, as well as phase center variations (PCVs) as a function of the elevation angle. The correction values could be derived from the GPS data collected on a short baseline with the reference antenna AOAD/M_T (Allen Osborne Associates Dorne Margolin T) at one end of the baseline and the antenna to be calibrated on the other (Mader 1999). Corrections from relative calibrations had been used until 5 November 2006 (Gendt 2006) despite the arbitrary assumption that the PCVs of the reference antenna were zero and other limitations of the procedure resulting in systematic errors (Schmid et al. 2005a).

The transition to absolute receiver antenna phase center corrections in November 2006 permitted to avoid these problems. Corrections that do not depend on a reference antenna can be obtained from two completely independent approaches. Former calibrations in anechoic chambers (e.g. Schupler et al. 1994) were verified by field measurements on a short baseline using a robot capable of tilting and rotating one of the antennas (Menge et al. 1998). Although the results were in good agreement (Rothacher 2001), they were not immediately adopted for general use, as their application was found to give a global GPS frame differing from very long baseline interferometry (VLBI) and satellite laser ranging (SLR) in scale by about 15 ppb (e.g. Springer 2000a).

It was suggested by several people (e.g. Springer 2000b; Rothacher 2001) that the neglect of the behavior of the transmitting antennas on-board the GPS satellites might explain the failure of the absolute phase center corrections for the tracking antennas attached to GPS receivers on the ground. Within the IGS, one standard offset of the phase center with respect to the center of mass per satellite block was used at that time (Kouba 2003). Nadir- or azimuth-dependent PCVs were completely ignored, although the antenna assembly of 12 helical elements indicates non-perfectly hemispherical signal wavefronts (Czopek and Shollenberger 1993). Since the effort of Mader and Czopek (2002) to calibrate a spare Block IIA antenna on ground did not result in adequate accuracy, the satellite antenna characteristics had to be determined from the GPS data together with other geodetic parameters usually set up in global solutions.

However, this problem is singular due to very high correlations between station heights, tropospheric parameters and the offsets and PCVs of the tracking and the transmitting antennas, respectively (Springer 2000b). A solution is only possible if the terrestrial scale is fixed by adopting a set of fiducial coordinates for the tracking network and if absolute receiver antenna phase center corrections are taken from external calibration measurements. Schmid and Rothacher (2003) demonstrated the possibility to estimate nadir-dependent PCVs for the satellite antennas by adopting the international terrestrial reference frame ITRF2000 scale (Altamimi et al. 2002) and absolute robot calibrations for the tracking antennas. Also the existence of azimuth-dependent PCVs could be verified (Schmid et al. 2005b). As the ionosphere-free linear combination $\mathrm{LC}$ had to be formed in order to eliminate the ionospheric refraction, their satellite antenna corrections referred to LC.

Whereas the latter work was limited to phase center corrections for the three different satellite blocks (Block I, II/IIA, IIR), Ge and Gendt (2005a) pointed out that it was not sufficient to use block-specific correction values. Due to significant differences between individual satellites, mainly in the offset in $z$-direction pointing toward the Earth, satellite-specific corrections are necessary. However, time series for satellite-specific offsets from the reprocessing of global GPS networks (Ge et al. 2005b; Steigenberger et al. 2006) showed trends and long-periodic signals caused by inconsistencies in the scale definition and the orbit modeling. Therefore, long time series are essential in order to get the best possible mean phase center corrections for all satellites available.

In order to fulfil the recommendation from the IGS 2004 Workshop and Symposium in Bern to assemble a consistent set of absolute phase center corrections to allow for a test phase amongst the ACs (Schmid et al. 2005a), the Technische Universität München (TUM) and the IGS AC located at the GeoForschungsZentrum Potsdam (GFZ) decided to reprocess tracking data since the official start of the IGS in 1994, and to combine the results gained from two independent software packages using different strategies. At the same time, the Jet Propulsion Laboratory (JPL) succeeded in deriving PCV maps from post-fit tracking data residuals of the antennas on-board Jason-1 and the GRACE 
satellites for both the carrier-phase and code pseudorange data types (Haines et al. 2004). Those maps are two-dimensional (depending on nadir and azimuth angle), but naturally only available for the GPS satellites active since 2002 .

A transition from relative to absolute antenna phase center corrections implicates several positive aspects. As the modeling of one of the various elevation-dependent effects is improved, GPS results are less dependent on the selected elevation cut-off angle (Schmid et al. 2005b). Furthermore, any correlated parameter should benefit. For example, Schmid et al. (2005b) demonstrated a significant reduction of tropospheric zenith delay biases between GPS and VLBI, and Ge et al. (2005b) illustrated the stabilization of the global terrestrial scale.

At the same time as absolute phase center corrections were adopted, the IGS began to consider the effect of radomes that protect receiver antennas from environmental impacts. Although it is well known that the impact of radomes on the phase center position can amount to several cm (e.g. Braun et al. 1997), it was more or less ignored up to November 2006 (Schmid et al. 2005a). In particular, ignoring radomes has a dramatic effect on vectors between co-located techniques, the so-called local ties (Ray and Altamimi 2005; Ray et al. 2007). However, these vectors are the crucial links for the combination of the different space geodetic techniques. As calibrations for several combinations of antenna and radome in use are missing and as some combinations are not even calibratable, this problem will persist.

This paper describes the compilation of the consistent absolute antenna correction file for the IGS test phase. After a short introduction to the receiver antenna corrections, different satellite blocks and software packages used (Sect. 2), we present several problems and specialties in connection with long time series of satellite antenna offsets (Sect. 3). In Sect. 4, the satellite antenna PCV results from GFZ and TUM are compared, yielding block-specific correction curves. Those values serve as the basis for the determination of satellite-specific $z$-offsets that have to be referenced to a given epoch due to considerable trends in the time series (Sect. 5). Finally, we demonstrate how the estimation of troposphere and orbit parameters, station coordinates and the terrestrial scale benefit from the new phase center model (Sect. 6).

\section{Input data, software packages, strategy}

\subsection{Receiver antenna PCVs}

The receiver antenna phase center information that was fixed for the work presented here is identical to the corrections contained in the file igs05_1365.atx (available at ftp://igscb.jpl.nasa.gov/ igscb/station/general/pcv_proposed/) except for several radome calibrations (see below). Besides the satellite antenna information, this file contains absolute calibration values for 154 different receiver antenna types in total. Those are composed of 106 antennas without a radome and 48 combinations of an antenna with one particular radome. Among the 106 different antenna types, there are only 32 that possess robot calibration results including both zenithal and azimuthal PCVs (Menge et al. 1998). However, these 32 antennas include most of the types dominating the IGS tracking network.

In order to generate a complete set of phase center corrections for tracking antennas, the robot calibrations had to be complemented by results from relative field calibrations (Mader 1999). The latter had to be converted to absolute corrections by adding the difference between the absolute and the relative values for the reference antenna AOAD/M_T (Menge 2003). Equations (1) and (2) give the conversion formulae for the phase center offset $(\mathrm{PCO})$ and the PCVs, respectively. The relative PCVs for the reference antenna are omitted from Eq. (2) as they are assumed to be zero.

$$
\begin{aligned}
& \mathrm{PCO}_{a b s}=\mathrm{PCO}_{\text {rel }}+\left(\mathrm{PCO}_{\mathrm{abs}}\left(\operatorname{AOAD} / \mathrm{M}_{\_} \mathrm{T}\right)-\mathrm{PCO}_{\text {rel }}\left(\operatorname{AOAD} / \mathrm{M}_{-} \mathrm{T}\right)\right) \\
& \mathrm{PCV}_{\text {abs }}=\mathrm{PCV}_{\text {rel }}+\mathrm{PCV}_{\text {abs }}\left(\mathrm{AOAD}_{\mathrm{M}} \mathrm{M}_{-} \mathrm{T}\right)
\end{aligned}
$$

As the relative field calibrations are limited to elevation angles above $10^{\circ}$ due to the error budget of low elevation observations, naturally the converted PCVs also only extend down to $10^{\circ}$. In contrast, robot PCVs are measured down to $0^{\circ}$ elevation.

It has to be noted that the calibrations for antenna/radome combinations were not added to the file igs05_wwww.atx (wwww: GPS week of the last file modification) until major parts of the work presented here had been finished. In the case of a radome mounted at a site, the calibration for the 
Table 1 Official satellite block designations (Navstar GPS Joint Program Office 2004), space vehicle numbers (SVNs) and manufacturers.

\begin{tabular}{lrl}
\hline Satellite block & SVNs & Manufacturer \\
\hline Block I & $1-11$ & Rockwell International \\
Block II & $13-21$ & Rockwell International \\
Block IIA & $22-40$ & Rockwell International \\
Block IIR/IIR-M & $41-61$ & Lockheed Martin \\
Block IIF & $62-73$ & Boeing \\
Prototype & 12 & Rockwell International \\
\hline
\end{tabular}

Table 2 IGS designations for the Block IIR satellites and the corresponding SVNs (Marquis and Reigh 2005).

\begin{tabular}{ll}
\hline Satellite antenna type & SVNs \\
\hline Block IIR-A & $41,43-46,51,54,56$ \\
Block IIR-B & $47,59-61$ \\
Block IIR-M & $48-50,52-53,55,57-58$ \\
Unsuccessful launch & 42 \\
\hline
\end{tabular}

antenna without the radome was used. This had also been the convention within the IGS for many years (Ray and Altamimi 2005). However, it may be expected that the consideration of radome calibrations will have minor influence on satellite antenna corrections. As Sect. 4 and 5 will show, the GFZ and TUM estimates agree very well although the tracking networks are different, and thus include different antenna/radome combinations.

\subsection{Satellite blocks}

According to the Navstar GPS Joint Program Office (2004), the space segment of the GPS system consists of six different satellite blocks (cf. Table 1). However, the last Block I satellite (SVN 10) was decommissioned on 18 November 1995 and the first Block IIF satellite will not be launched before 2008. That means that the current constellation consists of four different blocks (II, IIA, IIR, IIR-M). However, for our paper, Block IIR-M (M stands for modernized) could not be considered, as the first satellite was only launched on 26 September 2005.

As can be seen from Table 1, the GPS operators do not distinguish between the conventional Block IIR satellites and the modernized representatives of the same block as regards the space vehicle number (SVN). Moreover, the last four Block IIR satellites that were launched between December 2003 and November 2004 were retrofitted with the improved satellite antenna panel designed for the Block IIR-M satellites (Marquis and Reigh 2005). For this reason, the IGS decided to subdivide the conventional Block IIR satellites into two subgroups called Block IIR-A and Block IIR-B (see IGS naming convention rcvr_ant.tab available at ftp://igscb.jpl.nasa.gov/igscb/station/general/). The classification of the three different subgroups of Block IIR is given in Table 2. For the remaining satellite blocks, the official designations are used. Finally, it has to be noted that the antenna panels on-board the Block II and IIA satellites are supposed to be identical, just like the panels on-board Block IIR-B and IIR-M.

\subsection{Estimation strategies}

The reanalysis performed at GFZ to derive the antenna phase center models is based on the GFZ activities in the framework of the IGS TIGA (TIde GAuge benchmark monitoring) project (Schöne 2004). From the global network of more than 300 stations handled and cleaned within the TIGA reprocessing (Zhang et al. 2005), about 100 well distributed stations were used. TUM reprocessed a global GPS network in cooperation with the Dresden University of Technology (DUT; Steigenberger et al. 2006). Due to the high correlation between satellite antenna PCVs and PCOs, raw PCVs were estimated that correspond to the following sum: 


$$
\operatorname{PCV}_{\text {raw }}(\phi)=\mathrm{PCV}_{\text {min }}(\phi)+\Delta z \cdot(1-\cos \phi)
$$

The raw PCVs were finally converted into minimum PCVs and a $z$-offset forcing the PCV curves to be as flat as possible (Ge and Gendt 2005a). More details on the modeling and processing are given in Table 3.

\section{Estimation of satellite antenna phase center corrections}

\subsection{Attitude-related systematic effects}

Horizontal satellite antenna offsets are sometimes highly correlated with the orbital elements. E.g., depending on the position of the Sun with respect to the orbital plane, a small change of the horizontal PCO can easily be compensated by a change of the center of mass in the opposite direction. Therefore, the accuracy of the estimated horizontal offsets depends on the behavior of the attitude control of the GPS satellites, whereas the attitude control system is influenced by the orientation of the orbital planes with respect to the Sun.

Figure 1 shows the geometry of the Earth-fixed system, the orbit system and the satellite system (accompanying tripod of the satellite position). The elevation $\beta_{0}$ of the Sun above the orbital plane is given by

$$
\beta_{0}=90^{\circ}-\arccos \left(\left[\begin{array}{c}
\sin i \cdot \sin \Omega \\
-\sin i \cdot \cos \Omega \\
\cos i
\end{array}\right] \cdot\left[\begin{array}{c}
\cos \delta_{\odot} \cdot \cos \alpha_{\odot} \\
\cos \delta_{\odot} \cdot \sin \alpha_{\odot} \\
\sin \delta_{\odot}
\end{array}\right]\right)
$$

with the right ascension $\alpha_{\odot}$ and the declination $\delta_{\odot}$ of the Sun as well as the inclination $i$ and the right ascension of the ascending node $\Omega$ of the GPS satellite. According to Montenbruck and Gill (2000), the precession of the ascending node $\dot{\Omega}$ of a satellite (assuming a circular orbit: $e=0$ ) is given by

$$
\dot{\Omega}=-3 \pi \frac{J_{2}}{T}\left(\frac{R_{e}}{a}\right)^{2} \cdot \cos i
$$

with the orbital period $T$, the semi-major axis $a$, the inclination $i$, the radius of the Earth $R_{e}$ and the oblateness $J_{2}$. Inserting the corresponding values of the GPS satellites gives a rate of $\dot{\Omega}_{\mathrm{GPS}}=$ $-14.1^{\circ} / \mathrm{yr}$. That means that the annual period in $\beta_{0}$ caused by the periodic terms of the right ascension and declination of the Sun is superimposed with an oscillation due to the secular perturbation of $\Omega$. The beat period is $360^{\circ} /\left(14.1^{\circ} / \mathrm{yr}\right) \approx 25.5 \mathrm{yr}$. The limits of variation for the maximum $\beta_{0}$-angle $\beta_{0, \max }$ due to this beat frequency is given by the inclination of the GPS satellite $i$ and the obliquity of the ecliptic $\epsilon_{0}$

$$
\begin{aligned}
\left|\beta_{0, \text { max } \min \mid}\right| & =i-\epsilon_{0} \approx 31.5^{\circ} \\
\left|\beta_{0, \max , \max }\right| & =i+\epsilon_{0} \approx 78.5^{\circ}
\end{aligned}
$$

The elevation of the Sun for all GPS satellite orbits for the year 2003 is displayed in Fig. 2. The satellites in orbital plane B show the largest variations; those on plane E the smallest. The formal errors of the estimated horizontal offsets versus the elevation of the Sun $\beta_{0}$ are plotted in Fig. 3. The formal errors show a similar behavior: the largest formal errors occur for orbital plane B; the smallest for orbital plane $\mathrm{E}$. In addition, the formal errors of the satellites with large $\beta_{0}$-angles are larger for the $y$-offsets than for the $x$-offsets. These effects can be explained by the behavior of the GPS attitude control system.

The GPS attitude control system has two major tasks: (1) the transmitting antenna has to be pointed toward the center of the Earth (nadir direction) and (2) the vector perpendicular to the solar panels has to be pointed toward the Sun. For Block I and Block II/IIA satellites there is a third condition: the angle $\alpha$ between the Sun and the satellite's $z$-axis (see Fig. 1) has to be between $0^{\circ}$ and $180^{\circ}$. Block IIR satellites do not have that limitation anymore, thus the angle $\alpha$ may vary between $0^{\circ}$ and $360^{\circ}$ (Springer 2000a; Hugentobler et al. 2003). The compliance with these conditions is permanently controlled by Sun and Earth sensors and adjusted by the attitude control system. 
Table 3 Estimation strategies of GFZ and TUM.

\begin{tabular}{|c|c|c|}
\hline & GFZ & TUM \\
\hline Number of stations & $\begin{array}{l}\text { about } 100 \text { (from more than } 300 \text { TIGA } \\
\text { stations) }\end{array}$ & 195 (about $40-160$ per day) \\
\hline Time interval & 1 January 1994 - 1 March 2005 & 1 January 1994 - 31 December 2004 \\
\hline Software & $\begin{array}{l}\text { EPOS.P-V2 (Earth Parameters and } \\
\text { Orbit determination System; Gendt et } \\
\text { al. 1999) }\end{array}$ & $\begin{array}{l}\text { Bernese GPS Software Version } 5.0 \\
\text { (modified; Dach et al. 2007) }\end{array}$ \\
\hline Data & $\begin{array}{l}\text { zero-difference GPS carrier-phase and } \\
\text { code pseudo-range observations }\end{array}$ & $\begin{array}{l}\text { double-difference GPS carrier-phase } \\
\text { and code pseudo-range observations }\end{array}$ \\
\hline Sampling rate & 5 minutes & 3 minutes \\
\hline Elevation cut-off angle & & $3^{\circ}$ \\
\hline Weighting & $\begin{array}{l}\text { elevation-dependent (weight } w=4 . \\
\cos ^{2} z \text {, if zenith angle } z>60^{\circ} \text {, else } \\
w=1.0 \text { ) }\end{array}$ & $\begin{array}{l}\text { elevation-dependent (weight } w=\cos ^{2} z \\
\text { with zenith angle } z \text { ) }\end{array}$ \\
\hline Ambiguity fixing & $\begin{array}{l}\text { recently improved strategy resolving } \\
97 \% \text { of all ambiguities in the global net- } \\
\text { work (Ge et al. 2005c) }\end{array}$ & $\begin{array}{l}\text { ambiguities resolved in a baseline-by- } \\
\text { baseline mode; strategy depending on } \\
\text { the baseline length (Steigenberger et al. } \\
2006 \text { ) }\end{array}$ \\
\hline Station coordinates & $\begin{array}{l}\text { fixed to the reference frame IGb00 (Fer- } \\
\text { land 2003) }\end{array}$ & $\begin{array}{l}\text { no-net-rotation and no-net-scale condi- } \\
\text { tion for the IGb00 stations; thus, scale } \\
\text { fixed to IGb00 }\end{array}$ \\
\hline Orbits & $\begin{array}{l}24 \text {-hour orbital arcs; initial orbit posi- } \\
\text { tions and velocities, } 5 \text { radiation pres- } \\
\text { sure parameters of the model described } \\
\text { by Beutler et al. (1994) and pseudo- } \\
\text { stochastic pulses at } 12 \text { UT for each } \\
\text { satellite estimated }\end{array}$ & $\begin{array}{l}24 \text {-hour orbital arcs; } 6 \text { orbital ele- } \\
\text { ments, } 5 \text { radiation pressure parameters } \\
\text { of the model described by Beutler et al. } \\
\text { (1994) and pseudo-stochastic pulses at } \\
12 \text { UT for each satellite estimated }\end{array}$ \\
\hline Earth rotation & daily pole and length of day parameters & $\begin{array}{l}\text { set up at 2-hour intervals; pole coordi- } \\
\text { nates estimated freely except for block- } \\
\text { ing of retrograde diurnal terms (Hefty } \\
\text { et al. 2000); the first UT1-UTC param- } \\
\text { eter constrained to its a priori value } \\
\text { (IERS Bulletin A; Luzum et al. 2001) } \\
\text { due to correlations with the orbital el- } \\
\text { ements }\end{array}$ \\
\hline Ionospheric refraction & $\begin{array}{l}\text { first-order effect eliminated by forming } \\
\text { the ionosphere-free linear combination } \\
\text { LC; higher-order effects not corrected } \\
\text { for }\end{array}$ & $\begin{array}{l}\text { first-order effect eliminated by form- } \\
\text { ing the ionosphere-free linear combi- } \\
\text { nation LC; second- and third-order ef- } \\
\text { fects modeled according to Fritsche et } \\
\text { al. (2005) }\end{array}$ \\
\hline Tropospheric refraction & $\begin{array}{l}\text { a priori hydrostatic and wet delay } \\
\text { modeled with the Saastamoinen (1973) } \\
\text { model and a standard atmosphere } \\
\text { (pressure derived from station height, } \\
\text { temperature derived from latitude and } \\
\text { season); mapped to the zenith with } \\
\text { the corresponding Niell (1996) map- } \\
\text { ping functions; zenith delays at 4-hour } \\
\text { intervals and gradients in north-south } \\
\text { and east-west direction at 12-hour in- } \\
\text { tervals estimated as piece-wise con- } \\
\text { stant offsets using the hydrostatic Niell } \\
\text { (1996) mapping function }\end{array}$ & $\begin{array}{l}\text { a priori hydrostatic delay modeled with } \\
\text { the Saastamoinen (1973) model and } \\
\text { the standard atmosphere described by } \\
\text { Berg (1948) with a reference pressure } \\
\text { of } 1013.25 \mathrm{hPa} \text { at the ellipsoidal ref- } \\
\text { erence height of } 0 \mathrm{~m} \text {; mapped to the } \\
\text { zenith with the hydrostatic isobaric } \\
\text { Niell (2000) mapping function com- } \\
\text { puted from NCEP (National Centers } \\
\text { for Environmental Prediction) z200 da- } \\
\text { ta (height of the } 200 \mathrm{hPa} \text { pressure } \\
\text { level; Saha et al. } 2006) \text {; zenith delays } \\
\text { at 2-hour intervals and gradients in } \\
\text { north-south and east-west direction at } \\
\text { 24-hour intervals estimated as contin- } \\
\text { uous piece-wise linear functions using } \\
\text { the wet Niell (1996) mapping function }\end{array}$ \\
\hline Satellite antenna PCVs & \multirow{2}{*}{\multicolumn{2}{|c|}{$\begin{array}{l}\text { satellite-specific, nadir-dependent estimation; } \phi_{\max }=14^{\circ} ; 1^{\circ} \text {-resolution; a priori } \\
\text { values from Schmid and Rothacher (2003); fixed to result from Sect. } 4 \text { when } \\
\text { estimating PCOs (Sect. 5) } \\
\text { a priori values: } \Delta z_{\mathrm{I}}=2.1965 \mathrm{~m}, \Delta z_{\mathrm{II} / \mathrm{IIA}}=2.3384 \mathrm{~m}, \Delta z_{\mathrm{IIR}}=1.3326 \mathrm{~m} \text { (Schmid } \\
\text { and Rothacher } 2003 \text { ); fixed when estimating PCVs (Sect. 4) }\end{array}$}} \\
\hline Satellite antenna PCOs & & \\
\hline Receiver antenna PCVs & \multicolumn{2}{|c|}{$\begin{array}{l}\text { If no PCVs are available below a } 10^{\circ} \text { elevation for the receiver antenna (see } \\
\text { Sect. 2.1), observations are corrected with the value given for } 10^{\circ} \text {. }\end{array}$} \\
\hline
\end{tabular}




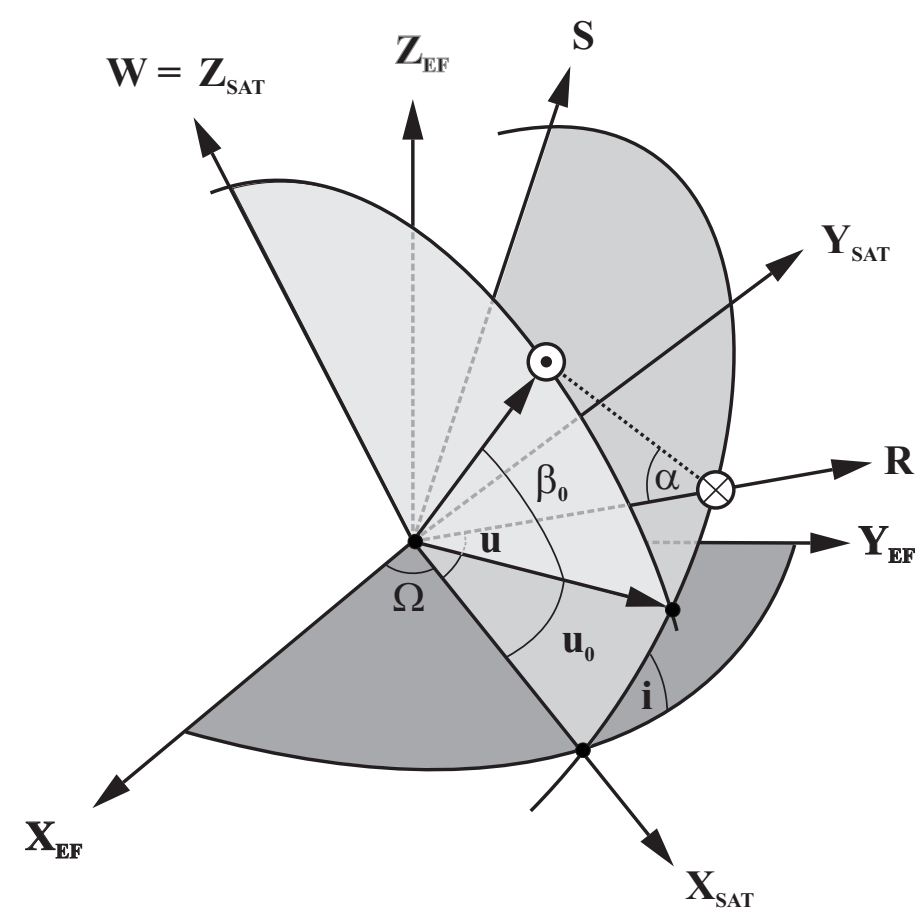

Fig. 1 Elevation of the Sun with respect to the orbital plane: Earth-fixed system $\left[X_{\mathrm{EF}}, Y_{\mathrm{EF}}, Z_{\mathrm{EF}}\right]$, orbit system $\left[X_{\mathrm{SAT}}, Y_{\mathrm{SAT}}, Z_{\mathrm{SAT}}\right]$, satellite system $[R, S, W]$. Right ascension of the ascending node $\Omega$, argument of latitude $u$, inclination $i$, argument of latitude $u_{0}$ and elevation $\beta_{0}$ of the Sun. $\odot$ symbolizes the Sun, $\otimes$ the satellite.

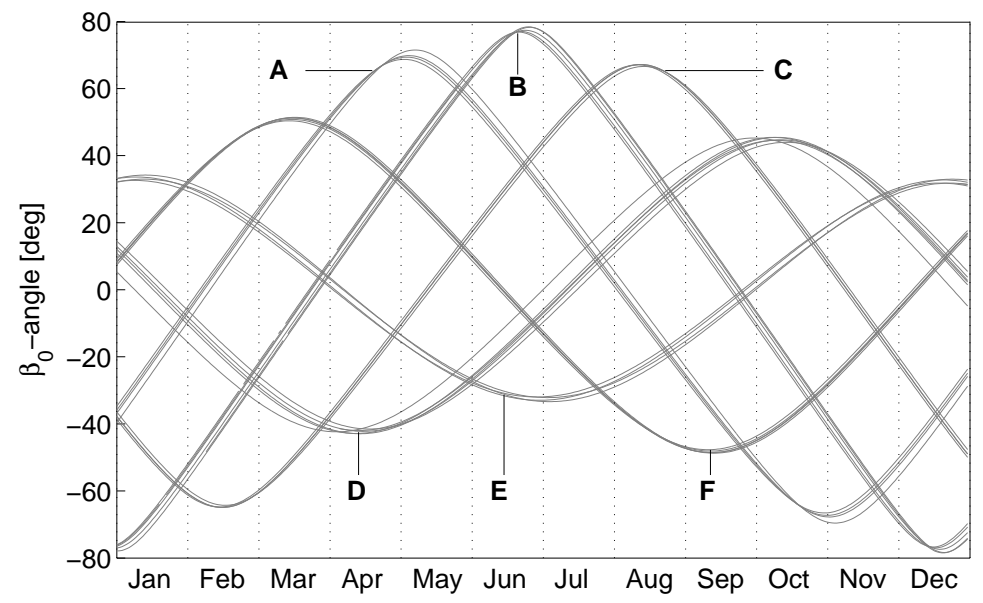

Fig. 2 Elevation of the Sun $\beta_{0}$ with respect to the orbital planes (A to F) for all GPS satellites in 2003.

During periods with the angle between the along-track direction and the satellite's $x$ - or $y$-axis close to $0^{\circ}$ or $180^{\circ}$ the decorrelation of the horizontal satellite antenna offsets and the along-track direction is a severe problem. This situation can occur during periods where the elevation of the Sun above the orbital plane is large. The angles $\gamma_{x}$ between the $x$-axis and the along-track direction and $\gamma_{y}$ between the $y$-axis and the along-track direction for one satellite with small (SVN 54, orbit plane E) and one satellite with large (SVN 30, orbit plane B) variations of the $\beta_{0}$-angle are shown in Fig. 4. Only in the case of a large $\beta_{0}$-angle, an angle $\gamma_{y}$ close to $0^{\circ}$ or $180^{\circ}$ occurs over longer periods of time; $\gamma_{x}$ behaves differently. This geometry-related effect explains the larger formal errors of the $y$-offsets estimated during periods with large $\beta_{0}$-angles visible in Fig. 3 (b), whereas the maximum of the formal errors of the $x$-offsets is smaller (Fig. 3 (a)). 

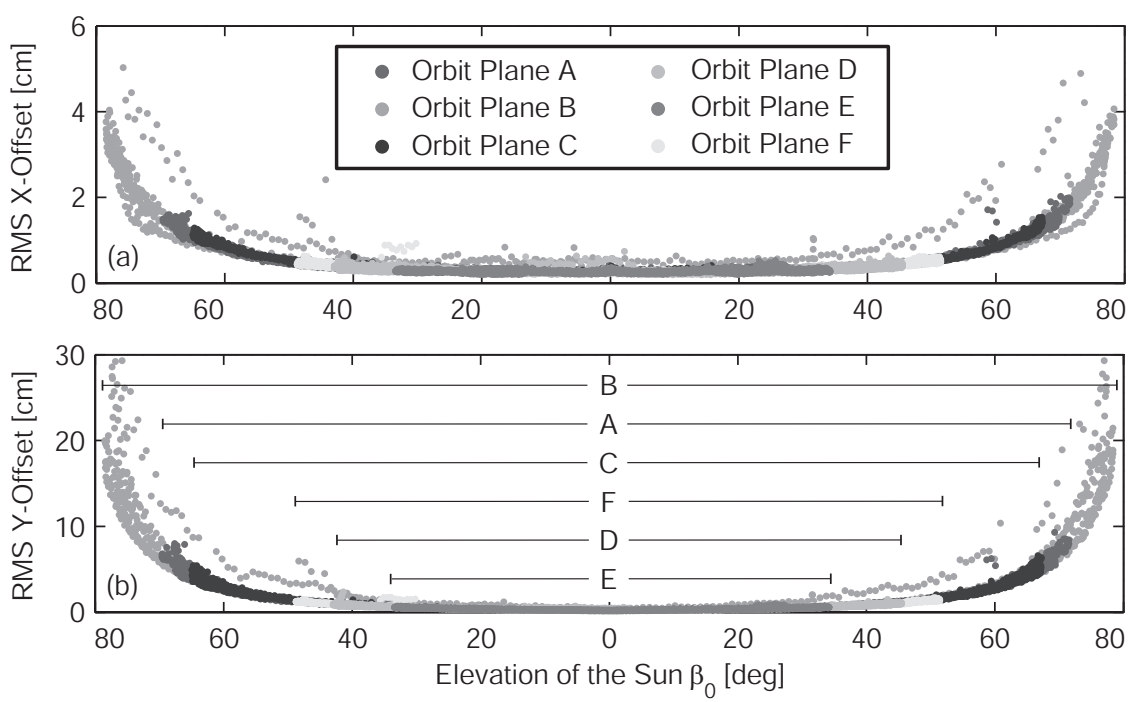

Fig. 3 Formal errors of the horizontal offset estimates versus elevation of the Sun $\beta_{0}$ for 2003 .

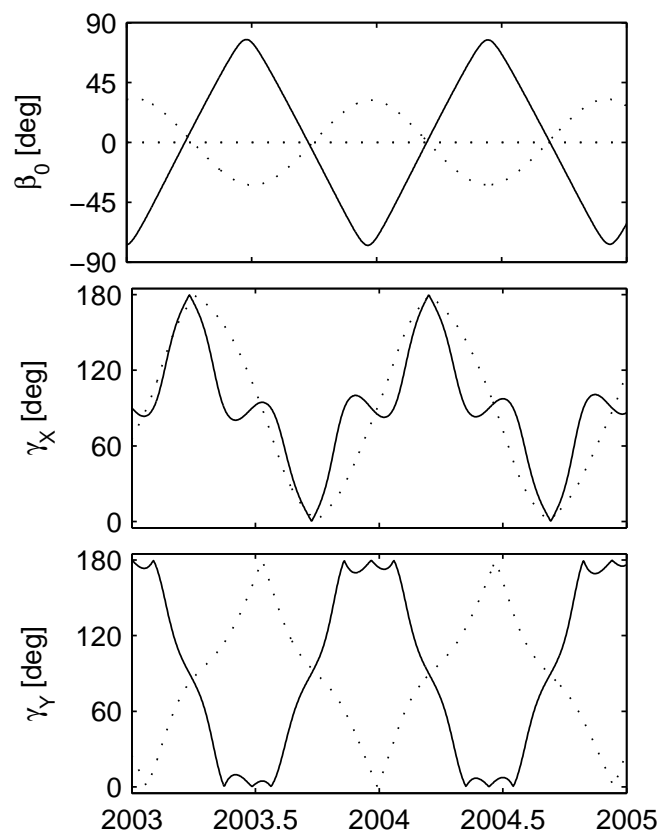

Fig. 4 Elevation of the Sun $\beta_{0}$ together with the angles $\gamma_{x}$ between the $x$-axis and the along-track direction and $\gamma_{y}$ between the $y$-axis and the along-track direction (each with one value at 0:00 UT per day) for SVN 30 (solid line) and SVN 54 (dashed line).

Also during eclipse seasons (angle $\alpha$ below about $14^{\circ}$, see Fig. 1), systematic effects arise when the solar panels cannot be oriented toward the Sun. To stabilize the satellite's attitude, the satellite starts to rotate with a rate of up to $0.12^{\circ} / \mathrm{s}$ (Bar-Sever 1995) around its $z$-axis. As the $y$-offsets are close to zero, they are only slightly biased by this unmodeled rotation. In contrast, the $x$-offsets of the Block I and Block II/IIA satellites (official IGS $x$-offsets of $21.0 \mathrm{~cm}$ and $27.9 \mathrm{~cm}$, respectively; Rothacher and Mader 2003) suffer heavily from this systematic effect, as one can see in Fig. 5 . The mean $x$-offset for SVN 37 (Fig. 5), including the eclipse seasons, is $29.7 \mathrm{~cm}$. The corresponding offset without the eclipse seasons is $32.7 \mathrm{~cm}$. Including data from eclipse seasons causes a systematic underestimation of 

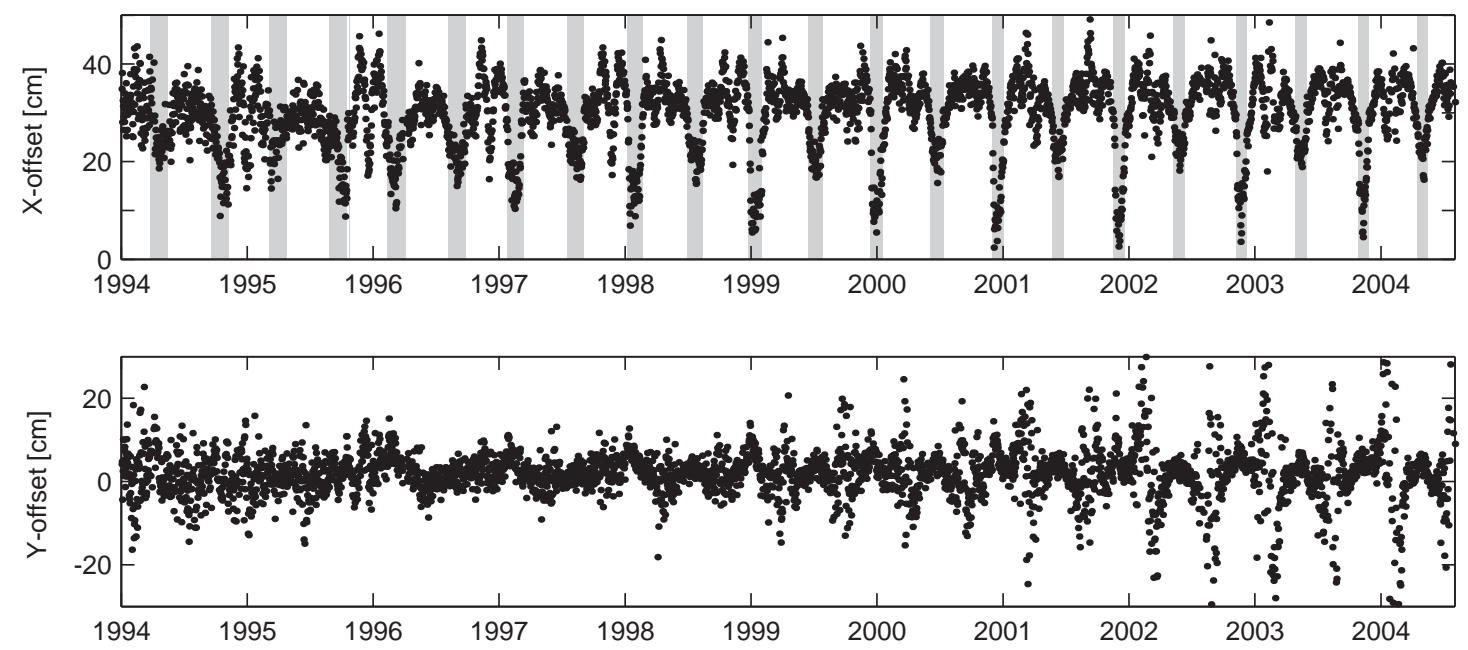

Fig. 5 Horizontal offset time series for SVN 37 (PRN 07). The eclipse seasons are gray-shaded. The maximum elevation of the Sun above the orbital plane $\beta_{0, \max }$ steadily increases after 1996 . This is reflected in increasing amplitudes of the peaks in the $y$-offset time series, particularly after 2000, when the absolute values of the maximum $\beta_{0}$-angle are larger than $50^{\circ}$.

the $x$-offsets (e.g., $3.0 \mathrm{~cm}$ for SVN 37). Therefore, these periods should be excluded when determining mean offsets.

\subsection{Correlations with orbit parameters}

Besides the eclipse seasons, further periodic signals are present in the horizontal offset time series of all satellites (independent of the block type) as well as in the $z$-offsets. The spectra of the offset time series for SVN 37 are shown in Fig. 6. The peaks in these spectra are related to the orientation of the orbital plane with respect to the Sun. Due to the precession of the ascending node $\dot{\Omega}$ (see Eq. 5) the time period $T_{R}$ between the same orientation of the orbital planes with respect to the Sun is shorter than one year:

$$
T_{R}=\frac{2 \pi}{2 \pi-\dot{\Omega}_{\mathrm{GPS}} \cdot 1 \mathrm{yr}} \cdot 365.25 \mathrm{~d} \approx 351.5 \mathrm{~d}
$$

Even after one sixth of this period, the constellation of the six orbital planes has approximately the same orientation, though the individual orbital planes differ. The main period of $T_{R}=351.5 \mathrm{~d}$ and its integer fractions $T_{R} / n, n=2, \ldots, 6$ are clearly visible in the spectra of the horizontal offsets in Fig. 6. For the $z$-offsets, the peaks are not as sharp as for the horizontal offsets, but most periods are also present in the vertical offset spectrum (Fig. 6). The amplitudes of the different periods vary from satellite to satellite. The amplitude of this signal also depends on the maximum value of the $\beta_{0}$-angle.

\subsection{Correlation with the global terrestrial scale}

As already mentioned in Sect. 1, there is a high correlation between the satellite antenna phase center $z$-offset and the scale of the reference frame, i.e. the station heights. According to Zhu et al. (2003), a change in the $z$-offset by $\Delta z$ for all satellites will result in a station height change $\Delta r$ of

$$
\Delta r \approx-0.05 \cdot \Delta z
$$

i.e., a change of $\Delta z=10 \mathrm{~cm}$ will change $\Delta r$ by $-5 \mathrm{~mm}$. Thus, the estimation of satellite antenna phase center corrections is only possible, if the terrestrial scale is fixed. However, that means that the scale from GPS remains doubtful as long as PCOs and PCVs are not available from independent calibration techniques. 

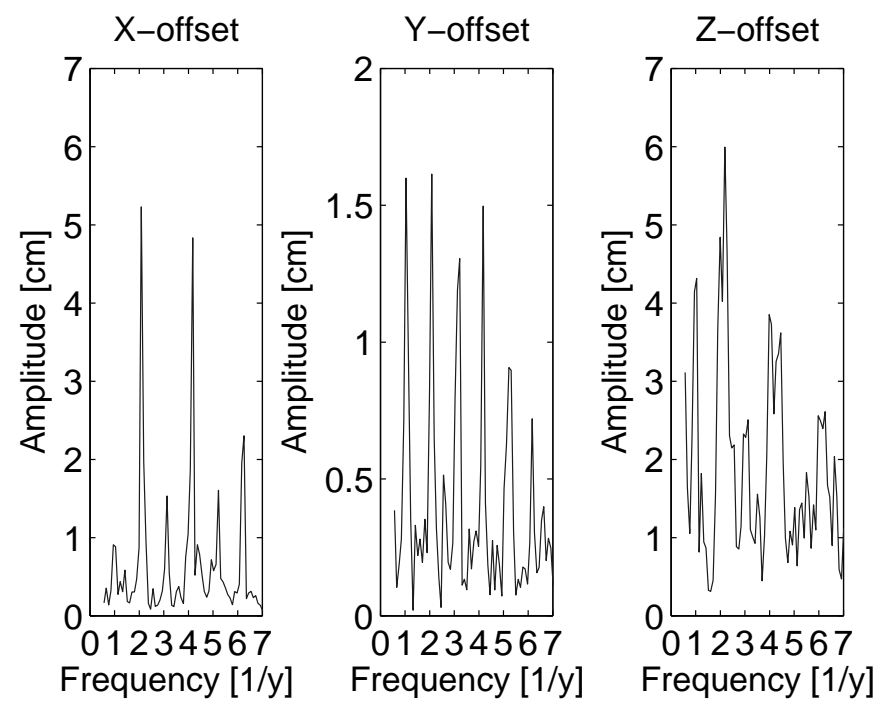

Fig. 6 Amplitude spectra of the antenna offsets for SVN 37.

\subsection{Insufficient accuracy from short time series}

The GFZ and TUM estimates show a significant trend in the $z$-offset time series (mean values of -2.2 and $-2.5 \mathrm{~cm} / \mathrm{yr}$, respectively; cf. Fig. 10 and 11). This trend is caused by errors in the vertical rates of the reference frame realization IGb00 (0.8 mm/yr; Ray et al. 2004). For the combined solution, the trend has been corrected for (see Sect. 5.2).

In addition to the effects described above, other signals seem to be present in the offset time series whose origin is not yet known. Due to all these systematic effects, short (below one year) time series are not adequate to determine mean PCOs. Averaging over long (multi-year) time series and excluding certain time periods (e.g., eclipses) helps to mitigate these effects.

\section{Satellite antenna phase center variations}

As shown in Eq. (3), there is a high correlation between nadir-dependent PCVs and the PCO in $z$-direction. Furthermore, azimuth-dependent PCVs that are not considered here are highly correlated with the $x$ - and $y$-offset (Schmid et al. 2005b). As long as the values for the PCO and its variations are used in a consistent manner, the partitioning of the overall phase center correction into PCO and PCVs is arbitrary. We decided to define the satellite antenna PCO such that the PCVs are minimized over the whole range of the nadir angle. Another possibility would be to minimize the PCVs for nadir angles above about $10^{\circ}$, where most of the observations are made, in order to keep the error as small as possible for those ignoring the PCVs.

In addition, it had to be decided whether block- or satellite-specific values should be determined for the phase center corrections. It turned out that the daily and weekly estimates for the PCVs of one specific satellite (see Fig. 7) as well as the mean PCVs for each satellite of one specific satellite block (see Fig. 8) agree almost perfectly, if satellite-specific $z$-offsets are allowed for in each 1-day solution. It has to be noted that these daily $z$-offset estimates may differ considerably from day to day (see Fig. 10). In order to reduce the number of model parameters, the satellite-specific PCVs were averaged (unweighted) in order to get block-specific ones, while keeping the satellite-specific PCOs. Due to the relationship between PCVs and the PCO (Eq. 3) it would also be possible to define block-specific $z$-offsets and to shift all the phase center differences between individual satellites to satellite-specific PCVs. However, many more parameters would then have to be determined.

In a first step, mean PCVs were computed for each individual satellite by GFZ and TUM from all data available (SVN 43 is shown in Fig. 7 as an example). Afterwards, both institutions separately averaged (unweighted) those values for each individual satellite block (Block IIR-A and IIR-B are 


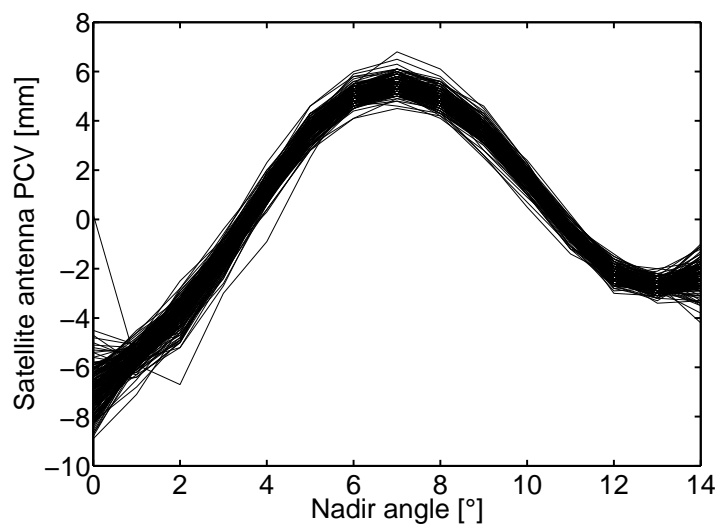

Fig. 7175 weekly PCV solutions for SVN 43 (Block IIR-A), each computed by GFZ from at least 4 daily solutions.

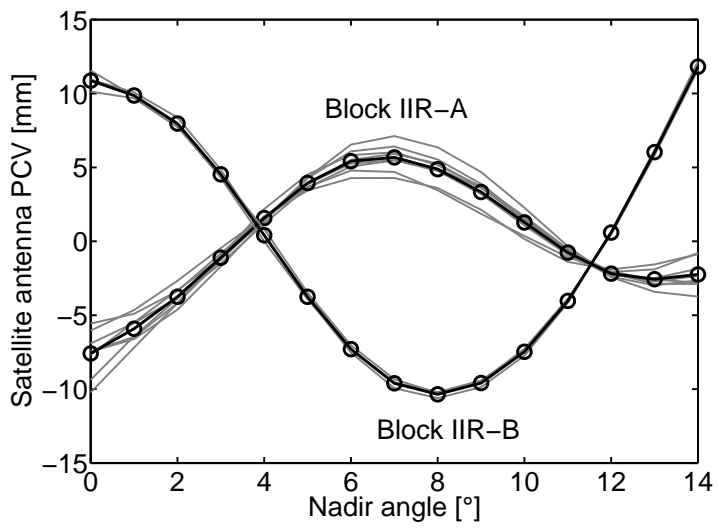

Fig. 8 Satellite-specific PCV solutions from GFZ for all Block IIR-A and IIR-B satellites together with the respective means indicated by circles.

shown in Fig. 8). In the case of GFZ, the mean standard deviations for one single PCV value from this averaging are $0.7 \mathrm{~mm}$ for Block I, II/IIA and IIR-A and $0.3 \mathrm{~mm}$ for Block IIR-B. These figures, as well as the graphs for the latter two blocks shown in Fig. 8, indicate that the modernized antenna panels on-board the latest satellites (cf. Sect. 2.2) are of high quality as they show the smallest variations between individual satellites. Furthermore, the comparatively large PCV values for Block IIR-B make it clear that satellite antenna PCVs have to be taken into account for high-precision applications.

Finally, the block-specific PCVs from GFZ and TUM were averaged to get the final result given in Fig. 9 and Table 4. The error bars displayed in Fig. 9 characterize the difference between the two independent solutions from different software packages. The mean differences are $0.6 \mathrm{~mm}$ for Block I, $0.3 \mathrm{~mm}$ for Block II/IIA, $1.1 \mathrm{~mm}$ for Block IIR-A and $0.2 \mathrm{~mm}$ for Block IIR-B. Except for several values of Block IIR-A and the peak at $1^{\circ}$ of Block I the agreement is rather excellent. The mean block-specific PCV values were finally fixed when reprocessing the complete GPS data once again, in order to derive best possible satellite-specific $z$-offsets (see Sect. 5). It should be pointed out that all satellite antenna parameters, PCVs and PCOs, refer to the ionosphere-free linear combination LC, as it was not possible to estimate separate corrections for L1 and L2.

\section{Satellite antenna phase center offsets}

5.1 Phase center $x$ - and $y$-offsets

Although Sect. 3 contains several aspects concerning the satellite antenna offsets in the $x$ - and $y$-directions, they are not considered in detail here. On the one hand, the deviations from the nominal values 


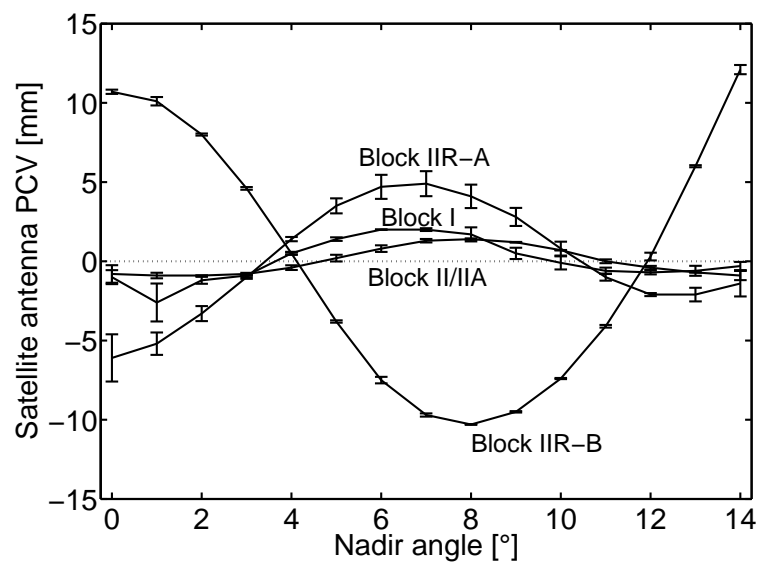

Fig. 9 Mean LC PCVs for all GPS satellite blocks with error bars indicating the difference between the GFZ and the TUM solution.

Table 4 Mean LC PCVs [mm] for all GPS satellite blocks.

\begin{tabular}{lccccccccccccccc}
\hline Nadir angle $\left[^{\circ}\right]$ & 0 & \multicolumn{1}{c}{1} & \multicolumn{1}{c}{2} & \multicolumn{1}{c}{3} & \multicolumn{1}{c}{5} & \multicolumn{1}{c}{6} & 7 & \multicolumn{1}{c}{8} & \multicolumn{1}{c}{9} & \multicolumn{1}{c}{10} & \multicolumn{1}{c}{11} & \multicolumn{1}{c}{12} & \multicolumn{1}{c}{13} & \multicolumn{1}{c}{14} \\
\hline Block I & -1.0 & -2.6 & -1.2 & -0.9 & 0.5 & 1.4 & 2.0 & 2.0 & 1.7 & 0.5 & -0.1 & -0.6 & -0.7 & -0.6 & -0.3 \\
Block II/IIA & -0.8 & -0.9 & -0.9 & -0.8 & -0.4 & 0.2 & 0.8 & 1.3 & 1.4 & 1.2 & 0.7 & 0.0 & -0.4 & -0.7 & -0.9 \\
Block IIR-A & -6.1 & -5.2 & -3.3 & -1.0 & 1.4 & 3.5 & 4.7 & 4.9 & 4.1 & 2.8 & 0.8 & -1.0 & -2.1 & -2.1 & -1.4 \\
Block IIR-B/M & 10.7 & 10.1 & 8.0 & 4.6 & 0.5 & -3.8 & -7.5 & -9.7 & -10.3 & -9.5 & -7.4 & -4.1 & 0.3 & 6.0 & 12.1 \\
\hline
\end{tabular}

did not appear to be significant in most cases, and on the other hand, it would only make sense to take them into account if also azimuth-dependent PCVs were considered. The only satellite that could be identified to have a horizontal offset differing considerably from the nominal value was SVN 23, which has a problem with its solar panels (Hugentobler et al. 2003).

\subsection{Trend in the $z$-offsets and the scale of the reference frame}

Figure 10 shows, as an example, the z-offset time series for GFZ and TUM with respect to the corresponding mean PCVs. One can easily see a trend in the offset amounting to about $20 \mathrm{~cm}$ after 10 years and a seasonal fluctuation. The reason for the seasonal pattern is not fully clear. Major candidates are local multipath or unmodeled loading effects, which may amount to several $\mathrm{mm}$ in the station heights, unmodeled effects in the satellite orbital models, and deficiencies of the troposphere mapping functions (cf. Boehm et al. 2006). However, the influence of those effects on the PCO can be removed (reduced) by taking an average over a longer (multi-year) time interval. There are no significant changes in the PCOs depending on the PCV model used.

The mean $z$-offset trend over all satellites is $-22.0 \pm 0.1 \mathrm{~mm} / \mathrm{yr}$ and $-24.8 \pm 0.2 \mathrm{~mm} / \mathrm{yr}$ for GFZ and TUM, respectively, if the scale is fixed to IGb00. This trend of about $2 \mathrm{~cm} / \mathrm{yr}$ can be explained by the reported error in the mean vertical velocity of IGb00 of $0.8 \mathrm{~mm} / \mathrm{yr}$ (Ray et al. 2004). The scale drift of $0.15 \mathrm{ppb} / \mathrm{yr}$ between GPS reprocessed results using absolute phase center information and IGb00 (see Table 8) would also roughly correspond to $1 \mathrm{~mm} / \mathrm{yr}$ in the station heights and hence to roughly $2 \mathrm{~cm} / \mathrm{yr}$ in the $z$-offset (cf. Eq. 8). In another TUM solution, where a reference frame realization of our own was used, no significant $z$-offset trend $(-1 \mathrm{~mm} / \mathrm{yr}$ only) could be detected.

For comparing the GFZ and TUM results and for forming mean values from different solutions, the significant trend, caused by the scale rate in the IGS realization of ITRF2000, has to be corrected for. By referencing all the individual satellite $z$-offsets to a given epoch (2000.0), no scale change in the reference frame, especially if it depends on the changing satellite constellation, should be obtained anymore. A general constant bias may still exist, but for various applications, like sea level monitoring, a scale trend is much more troublesome. 


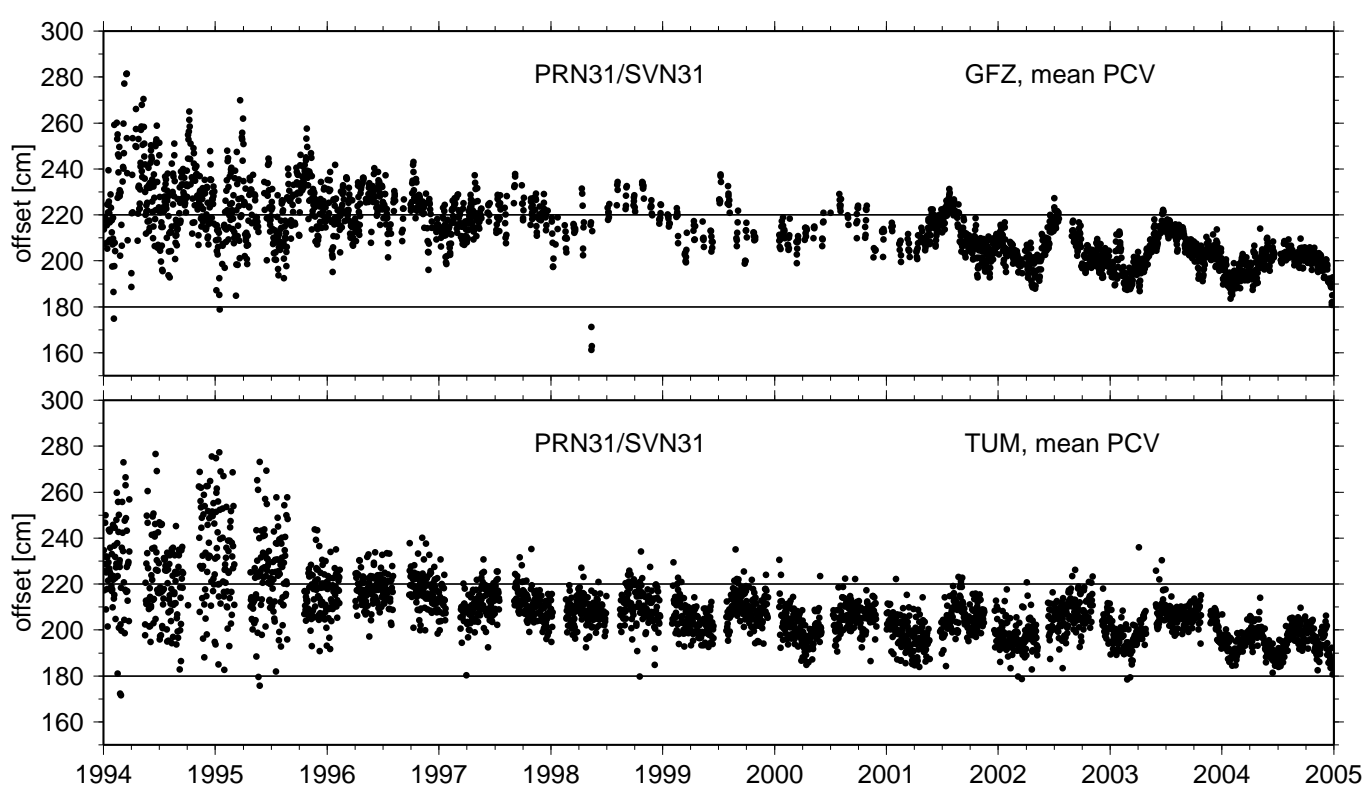

Fig. 10 Satellite antenna $z$-offset time series from GFZ (weekly means) and TUM (daily solutions) with station coordinates fixed to the IGb00 reference frame, both based on the mean PCVs (gaps in the TUM series due to the exclusion of eclipse seasons).

Table 5 Antenna $z$-offset differences (mean and standard deviation) between various solutions for the specific satellite blocks (I, II/IIA, IIR-A and IIR-B) and for all satellites (reference frame always fixed to IGb00).

\begin{tabular}{llllccccr}
\hline \multicolumn{2}{c}{ Solution 1 } & \multicolumn{2}{c}{ Solution 2 } & \multicolumn{5}{c}{ Differences [cm] } \\
AC & PCV & AC & PCV & I & II/IIA & IIR-A & IIR-B & \multicolumn{1}{c}{ All } \\
\hline TUM & mean & TUM & TUM & $13 \pm 8$ & $2 \pm 3$ & $-2 \pm 3$ & $1 \pm 2$ & $2 \pm 4$ \\
GFZ & mean & GFZ & GFZ & $-13 \pm 11$ & $1 \pm 3$ & $-6 \pm 4$ & $2 \pm 4$ & $-1 \pm 6$ \\
GFZ & GFZ & TUM & TUM & $18 \pm 4$ & $7 \pm 4$ & $7 \pm 2$ & $2 \pm 2$ & $7 \pm 5$ \\
GFZ & mean & TUM & mean & $-7 \pm 17$ & $6 \pm 3$ & $3 \pm 4$ & $2 \pm 2$ & $\mathbf{4} \pm \mathbf{6}$ \\
\hline
\end{tabular}

\subsection{Determination of satellite-specific $z$-offsets}

To get better insight into the behavior and the reliability of the derived satellite antenna phase center $z$-offsets, daily estimated values are used instead of stacking the NEQs and solving for a global parameter. In the latter case, also the trend resulting from the scale drift of the reference frame would have to be considered. Therefore, the simple but robust method of estimating daily offsets with a subsequent derivation of the mean offset and trend was selected. The daily offsets have a formal error of about $1.5 \mathrm{~cm}$ and the resulting mean offset and the offset trend estimated from the time series have errors of a few $\mathrm{mm}$ and $\mathrm{mm} / \mathrm{yr}$, respectively, depending on the length of the time series. These formal errors are rather optimistic and do not reflect the accuracy as the comparison between the results of the two software packages and different estimation strategies shows (Table 5). As known for a long time, the scale in the reference frame varies between solutions of the software packages (Altamimi et al. 2002) and this will also influence the differences in the estimated offsets.

For the individual satellites, the z-offset trends from the GFZ and TUM solutions are shown in Fig. 11. The formal errors of the trends are in the range of 2 to $5 \mathrm{~mm} / \mathrm{yr}$ and the agreement between GFZ and TUM is in most cases at the level of $1 \mathrm{~cm} / \mathrm{yr}$. Supposing that we have the same cause for the trend, e.g. IGb00, in all satellite offset series, it is of course much more stable (formal error of 0.1 to $0.2 \mathrm{~mm} / \mathrm{yr}$ ) to derive a common trend for all satellites.

Before generating the final combined solution, the effect of the given PCVs - AC own or mean - on the offsets was tested. From Table 5 and Fig. 12, it can be seen that the changes by switching from AC own to the mean PCVs is not significant and the overall change of a few $\mathrm{cm}$ is quite within the noise level of the procedure. The larger scatter for the Block I satellites is caused by the fewer observations 


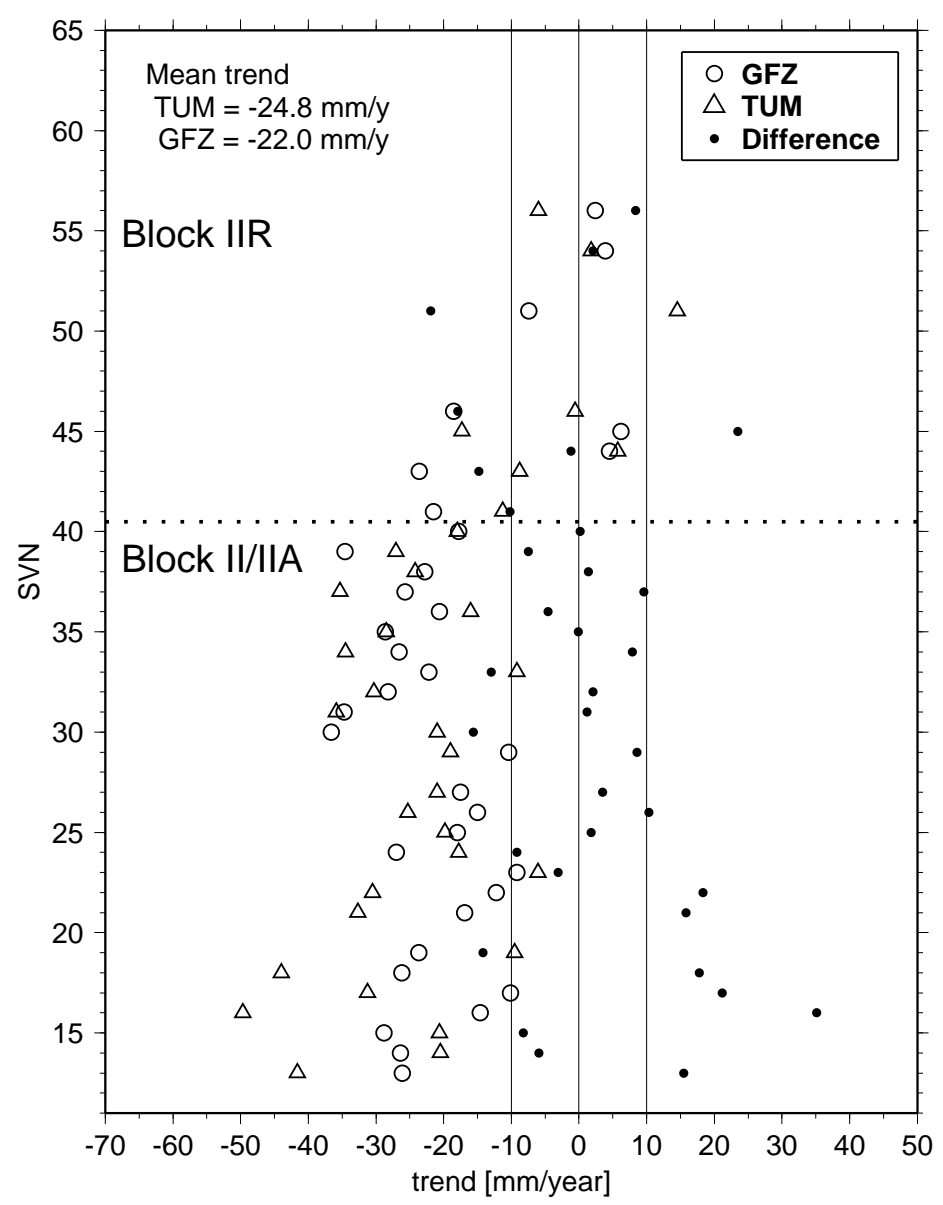

Fig. 11 Trends for satellite antenna $z$-offsets for individual satellites from GFZ and TUM using own PCVs and fixing the reference frame to IGb00. Only satellites with more than two years of data are shown. The formal trend error is in the range of 2 to $5 \mathrm{~mm} / \mathrm{yr}$.

used. The overall difference between the mean solutions of GFZ and TUM, $4 \mathrm{~cm}$ and a scatter of $6 \mathrm{~cm}$, demonstrate the high quality of the results (Table 5).

The mean $z$-offsets for the different blocks are, as already known from the IGS standard for the relative antenna model (Rothacher and Mader 2003), rather different (Table 7). But also within one block, the peak-to-peak difference between individual satellites reaches values of 60 and $70 \mathrm{~cm}$ for Block IIA and Block IIR, respectively (Table 6). There is especially a significant difference between the newer and the older Block IIR satellites (see Sect. 2.2), similar to what we have seen for the corresponding PCVs. Therefore, mean block-specific values for the $z$-offsets cannot reasonably be defined and we recommend the introduction of satellite-specific offsets. It can be assumed that those, in addition, absorb the differences between satellite-specific and block-specific PCVs to some extent, as PCOs and PCVs are tightly connected.

\subsection{Comparison with NGA values}

The National Geospatial-Intelligence Agency NGA (formerly NIMA) uses a set of satellite antenna PCOs that differs from the IGS conventional values. We cannot say anything definite about the origin of these values, but most likely they are the result of calibration measurements by the manufacturers on the ground. It is also unknown for which frequency they were measured. For Block II/IIA, only a block-specific mean offset is given, whereas for Block IIR satellite-specific values can be found on the NGA website (http://earth-info.nga.mil/GandG/sathtml/). 


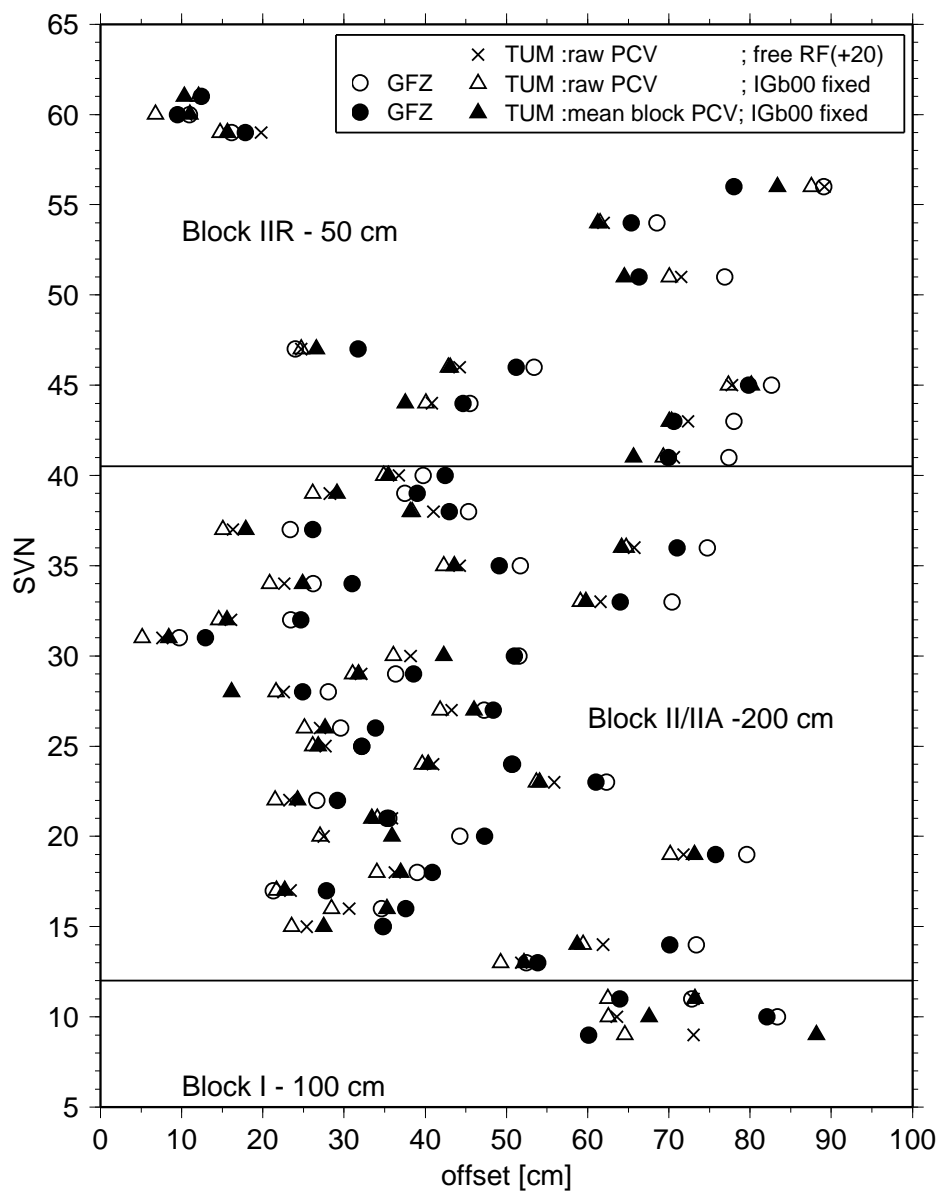

Fig. 12 Satellite antenna $z$-offsets from GFZ and TUM for different PCV models and reference frames used. The TUM solution based on an internal reference frame is shifted by $+20 \mathrm{~cm}$. The formal offset error ranges from 2 to $6 \mathrm{~mm}$.

If the mean block-specific $z$-offsets from the combined GFZ/TUM solution are compared with values from NGA and the IGS relative model (cf. Table 7), enormous differences appear between the diverse satellite blocks, but particularly between the three models. The GFZ/TUM and the NGA models agree in the fact that the Block IIR-B satellites have the smallest $z$-offset of all existing GPS satellites. However, there is a very big difference as regards Block II/IIA and Block IIR-A: the GFZ/TUM model detects a difference of $+125.14 \mathrm{~cm}$ between the two blocks in contrast to $-63.66 \mathrm{~cm}$ in the NGA model.

The comparison with the relative IGS model shows that the proportion of the offsets to each other agrees well for the first three blocks, indicating that the values used by the IGS until November 2006 are relatively consistent, even though Ge et al. (2005b) outline that the Block IIR-A offset should be about $40 \mathrm{~cm}$ smaller. However, the relative IGS model did not account for the offset difference between Block IIR-B and Block IIR-A as detected by the other two models: $-47.56 \mathrm{~cm}$ (GFZ/TUM) and $-159.85 \mathrm{~cm}$ (NGA), respectively. If this discrepancy had also been ignored for the Block IIR-M satellites to be launched, a considerable change of the global terrestrial scale would have had to be expected.

A closer look at the individual z-offsets of the Block IIR satellites shows that the new GFZ/TUM model and the NGA values are quite consistent. Figures 13 and 14 show the satellite-specific offsets of the two models for Block IIR-A and Block IIR-B, respectively. The individual satellites are arranged according to the size of their GFZ/TUM offset. In order to compensate for the different mean values (cf. Table 7) as well as the different ranges of values, a bias and a scale were allowed for in the representation of the two offset models. Except for SVN 45 and SVN 60, the agreement is almost 
Table 6 Mean antenna $z$-offsets $[\mathrm{cm}]$ and differences $[\mathrm{cm}]$ between GFZ and TUM for all satellites active between 1994 and 2005 (SVN: space vehicle number, PRN: pseudo-random noise number, BLK: satellite block designation).

\begin{tabular}{cclrr}
\hline SVN & PRN & BLK & Mean & \multicolumn{1}{c}{ Diff } \\
\hline 09 & G13 & I & 174.1 & -28.1 \\
10 & G12 & I & 174.8 & 14.5 \\
11 & G03 & I & 168.6 & -9.3 \\
13 & G02 & II & 253.0 & 1.7 \\
14 & G14 & II & 264.4 & 11.4 \\
15 & G15 & II & 231.2 & 7.3 \\
16 & G16 & II & 236.4 & 2.3 \\
17 & G17 & II & 225.3 & 5.2 \\
18 & G18 & II & 238.9 & 3.9 \\
19 & G19 & II & 274.4 & 2.6 \\
20 & G20 & II & 241.6 & 11.4 \\
21 & G21 & II & 234.4 & 1.9 \\
22 & G22 & IIA & 226.7 & 4.9 \\
23 & G23 & IIA & 257.5 & 6.9 \\
24 & G24 & IIA & 245.5 & 10.3 \\
25 & G25 & IIA & 229.5 & 5.4 \\
26 & G26 & IIA & 230.7 & 6.2 \\
27 & G27 & IIA & 247.2 & 2.4 \\
28 & G28 & IIA & 220.5 & 8.7 \\
29 & G29 & IIA & 235.2 & 6.8 \\
30 & G30 & IIA & 246.6 & 8.7 \\
31 & G31 & IIA & 210.7 & 4.5 \\
32 & G01 & IIA & 220.1 & 9.1 \\
33 & G03 & IIA & 261.9 & 4.3 \\
34 & G04 & IIA & 227.9 & 6.1 \\
35 & G05 & IIA & 246.3 & 5.5 \\
36 & G06 & IIA & 267.6 & 6.9 \\
37 & G07 & IIA & 222.0 & 8.2 \\
38 & G08 & IIA & 240.5 & 4.8 \\
39 & G09 & IIA & 234.0 & 9.9 \\
40 & G10 & IIA & 238.9 & 7.0 \\
41 & G14 & IIR-A & 117.8 & 4.3 \\
43 & G13 & IIR-A & 120.3 & 0.6 \\
44 & G28 & IIR-A & 91.1 & 7.1 \\
45 & G21 & IIR-A & 130.0 & -0.4 \\
46 & G11 & IIR-A & 97.1 & 8.2 \\
51 & G20 & IIR-A & 115.4 & 1.9 \\
54 & G18 & IIR-A & 113.3 & 4.1 \\
56 & G16 & IIR-A & 130.7 & -5.4 \\
47 & G22 & IIR-B & 79.2 & 5.2 \\
59 & G19 & IIR-B & 66.8 & 2.2 \\
60 & G23 & IIR-B & 60.2 & -1.6 \\
61 & G02 & IIR-B & 61.4 & 2.1 \\
\hline & & & &
\end{tabular}

Table 7 Comparison of the mean satellite antenna $z$-offsets [cm] from GFZ/TUM with NGA values and the relative IGS model.

\begin{tabular}{lrrr}
\hline Block & GFZ/TUM & \multicolumn{1}{c}{ NGA } & \multicolumn{1}{c}{ IGS } \\
\hline I & 172.50 & - & 85.40 \\
II/IIA & 239.60 & 95.19 & 102.30 \\
IIR-A & 114.46 & 158.85 & 0.00 \\
IIR-B & 66.90 & -1.00 & 0.00 \\
\hline
\end{tabular}




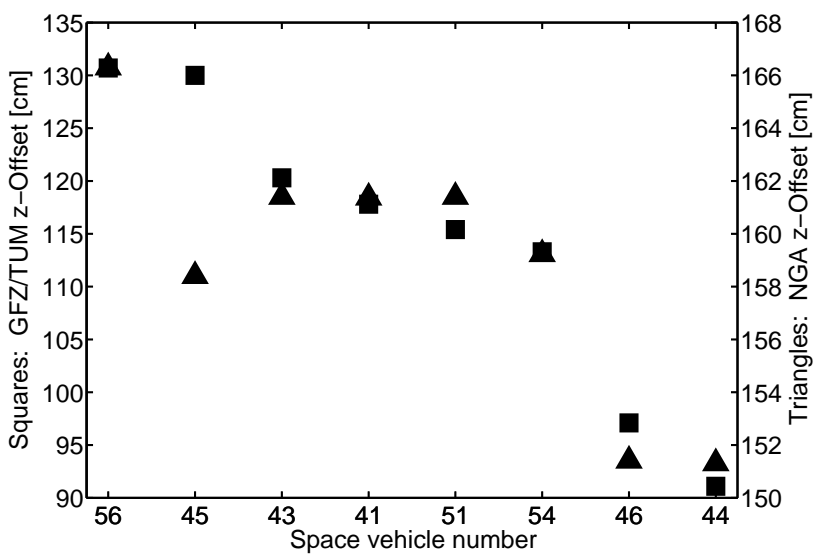

Fig. 13 Comparison of individual antenna $z$-offsets $[\mathrm{cm}]$ for all Block IIR-A satellites: the GFZ/TUM offsets are represented by squares with the scale on the left, whereas the scale for the triangles representing the NGA values is given on the right.

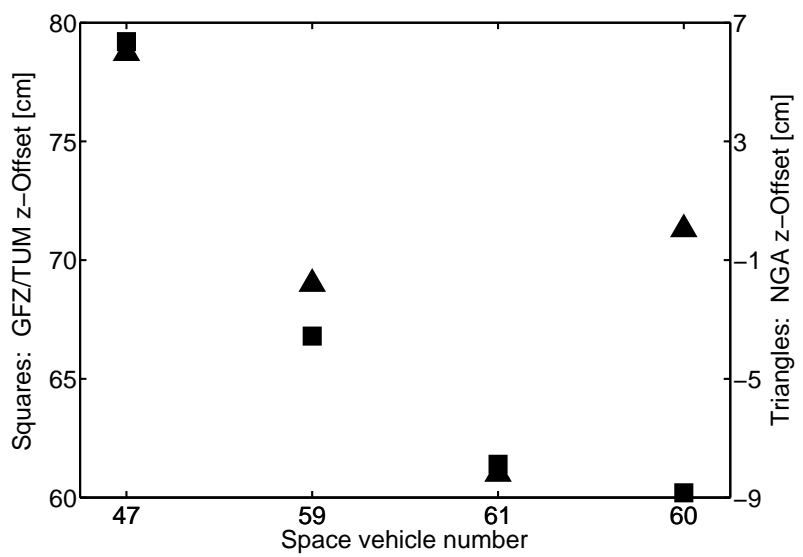

Fig. 14 Comparison of individual antenna $z$-offsets $[\mathrm{cm}]$ for all Block IIR-B satellites: the GFZ/TUM offsets are represented by squares with the scale on the left, whereas the scale for the triangles representing the NGA values is given on the right.

perfect in consideration of the fact that the TUM estimates for the Block IIR offsets differed from the GFZ ones by $2-3 \mathrm{~cm}$.

\section{Influence on global GPS parameters}

To study the influence of different antenna phase center corrections on global GPS parameters, four solutions covering the time interval from 1 January 1994 until 31 December 2004 were computed with completely identical settings, except for the PCVs and $z$-offsets used (Table 8 ).

The processing scheme is identical to the TUM strategy described in Sect. 2.3 except for three differences: (1) neither PCVs nor PCOs were estimated, (2) the scale was not fixed to IGb00 and (3) the hydrostatic isobaric mapping function was computed with ECMWF (European Centre for MediumRange Weather Forecasts) z200 data (available at http://mars.hg.tuwien.ac.at/ ecmwf1/Z200/). The relative PCV model used by the IGS until November 2006 was introduced for solution A. Solution B uses an older absolute PCV solution by TUM with block-specific offsets. Solution C is based on the TUM contribution to the combined GFZ/TUM PCV solution labeled D. The latter solution is the only one taking into account the influence of several antenna/radome combinations. 


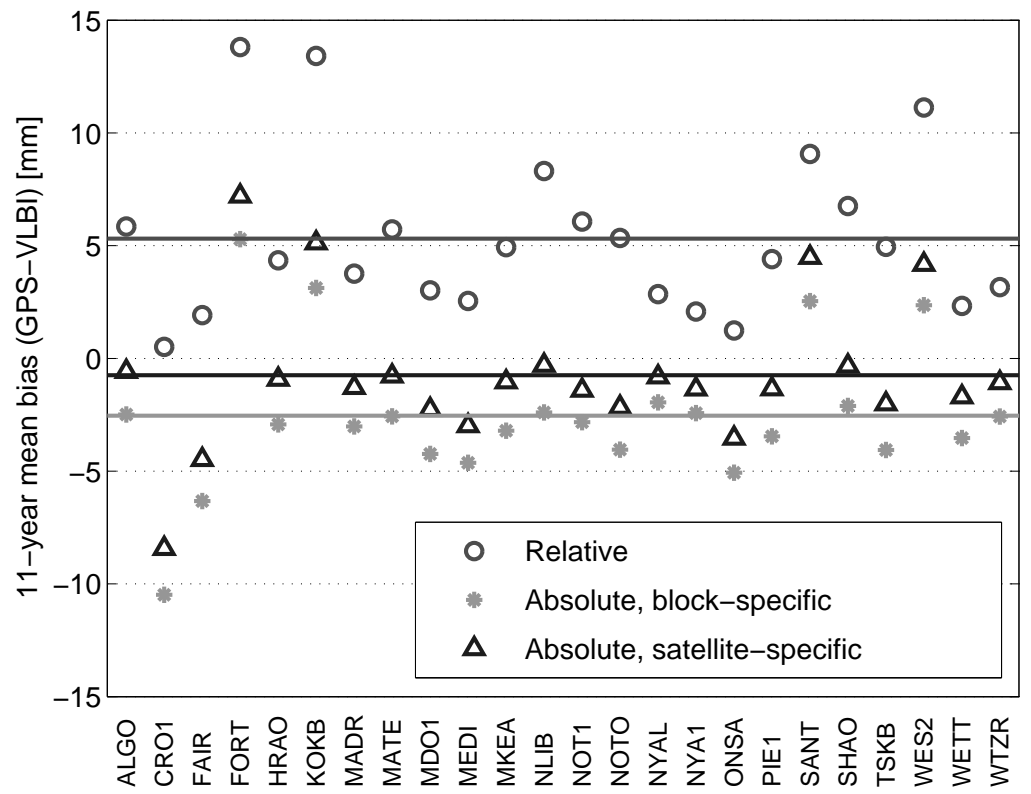

Fig. 15 Tropospheric zenith delay biases between GPS and VLBI for 24 co-located stations. The theoretical bias due to the height difference was corrected for. The mean biases (indicated by horizontal lines) are $+5.3 \pm$ $3.5 \mathrm{~mm}$ for relative PCVs (solution A), $-2.5 \pm 3.2 \mathrm{~mm}$ for absolute PCVs with block-specific $z$-offsets (solution B) and $-0.8 \pm 3.2 \mathrm{~mm}$ for absolute PCVs with satellite-specific $z$-offsets (solution C).

\subsection{Troposphere parameters}

The comparison of common parameters derived by different space geodetic techniques allows an assessment of the effects of different modeling approaches for technique-specific effects like antenna PCVs. The tropospheric zenith delays resulting from the GPS solutions A, B and C were compared to a VLBI solution computed by Deutsches Geodätisches Forschungsinstitut (DGFI, Tesmer et al. 2004). Identical a priori zenith delays for each station together with the Niell (1996) mapping function were used, both for GPS and VLBI. The theoretical difference in the tropospheric zenith delay due to the height difference between the GPS antenna and the VLBI telescope was corrected for with the Saastamoinen (1973) model (accurate to $1 \mathrm{~mm}$ for height differences below about $20 \mathrm{~m}$ ). The biases between GPS and VLBI for 24 co-located stations are shown in Fig. 15. The largest mean bias $(+5.3 \pm 3.5 \mathrm{~mm})$ occurs for relative PCVs (solution A); it can be reduced by more than a factor of two to $-2.5 \pm 3.2 \mathrm{~mm}$ by switching to absolute PCVs with block-specific z-offsets (solution B). A further improvement can be achieved by introducing satellite-specific $z$-offsets (solution $\mathrm{C}$ ): the bias can again be reduced by a factor of three to $-0.8 \pm 3.2 \mathrm{~mm}$. The tropospheric zenith delay biases of the eight stations participating in the continuous two-week VLBI campaign CONT02 (Thomas and MacMillan 2003) show an astonishingly good agreement with the 11-year time series (see Thaller et al. 2006). Remaining biases might be caused by changes in the antenna/radome constellation of the individual stations, by local multipath effects or by VLBI-related effects.

\subsection{Global terrestrial scale}

Scale offset and drift with respect to IGb00 of the four different global solutions are listed in Table 8 . The solution using relative PCVs (solution A) shows the well-known large offset (1.20 ppb; cf. Altamimi et al. 2002) and also a large drift of $0.34 \mathrm{ppb} / \mathrm{yr}$ caused by the erroneous standard offsets, especially for Block IIR, and the satellite constellation changing with time (Ge et al. 2005b). Both values are reduced by a factor of about two for solution B with absolute PCVs and block-specific $z$-offsets. Solution C has the smallest scale offset as well as the smallest drift due to the fact that the same software package was used, both for the estimation of the PCVs and the computation of the global solution. The combined GFZ/TUM PCV set used for solution D causes a slightly larger offset and drift than in solution C, 
Table 8 Global 11-year GPS solutions using different PCVs and $z$-offsets together with their scale offset and drift with respect to IGb00 on 1 January 2000 (b: block-specific, s: satellite-specific, z: zenith-dependent only, a: zenith- and azimuth-dependent).

\begin{tabular}{llccccccc}
\hline Sol. & & \multicolumn{4}{c}{ Antenna model } & & Offset [ppb] & Drift [ppb/yr] \\
ID & PCVs & Type & Sat.-PCVs & $z$-off. & Rec.-PCVs & Radomes & with respect to IGb00 \\
\hline A & IGS & relative & - & $\mathrm{b}$ & $\mathrm{z}$ & - & 1.20 & 0.34 \\
B & TUM & absolute & $\mathrm{b}$ & $\mathrm{b}$ & $\mathrm{a}$ & - & -0.65 & 0.18 \\
C & TUM & absolute & $\mathrm{b}$ & $\mathrm{s}$ & $\mathrm{a}$ & - & -0.10 & 0.12 \\
D & GFZ/TUM & absolute & $\mathrm{b}$ & $\mathrm{s}$ & $\mathrm{a}$ & $\mathrm{x}$ & 0.25 & 0.15 \\
\hline
\end{tabular}

but the reduction of the scale offset compared to solution A by a factor of almost five is a significant improvement. The remaining scale drift of $0.15 \mathrm{ppb} / \mathrm{yr}$ reflects the error of the IGb00 $(0.8 \mathrm{~mm} / \mathrm{yr})$ mentioned in Sect. 5.2.

\subsection{Orbit parameters}

An improved modeling of the satellite antenna phase center also affects the orbit quality. The RMS of a 3-day orbit fit through three 1-day orbital arcs was used to quantify the internal orbit consistency of the daily solutions. The mean RMS reduction within the 11-year time interval for each individual satellite when switching from relative PCVs (solution A) to absolute PCVs with block-specific (solution B) or satellite-specific z-offsets (solution D) is shown in Fig. 16. As expected, the Block IIR satellites, especially the Block IIR-B satellites, show the largest improvement in orbit consistency as they possess the largest PCV values (cf. Fig. 9). Due to the fact that no distinction was made between Block IIR-A and Block IIR-B for solution B, the improvement for the Block IIR-B satellites mainly shows up when comparing solutions A and D (Fig. 16). In the comparison of the solutions A and B, the two Block II satellites with the largest $z$-offsets (SVN 14 and 19) show a degradation of the RMS and for two Block IIA satellites with also large $z$-offsets (SVN 23 and 36) the RMS does not change. By additionally taking into account the $z$-offset variations within the different satellite blocks, the RMS reduction improves by a factor of about two for Block II/IIA and by a factor of 1.4 for Block IIR-A, emphasizing the importance of considering individual $z$-offsets.

\subsection{Station coordinates}

The mean coordinate changes between the solutions A and D for the whole 11-year time interval are shown in Fig. 17. Systematic effects due to different reference frame realizations of the two solutions were removed by a 3-parameter similarity transformation (translations only). The changes in the horizontal component range from -8 to $+6 \mathrm{~mm}$ for the north and from -5 to $+5 \mathrm{~mm}$ for the east component. A major part of these changes might be caused by considering azimuth-dependent receiver antenna PCVs for solution D that are neglected in solution A. The large mean change in the height component of $+6 \mathrm{~mm}$ is primarily related to the scale difference between the two solutions (offset on 1 January 2000: $0.95 \mathrm{ppb}$, drift: $0.19 \mathrm{ppb} / \mathrm{yr}$ ). The spectrum of changes in the station height ranging from -7 to $+18 \mathrm{~mm}$ is much broader than for the horizontal components. Especially some stations with calibrated radomes show large height changes.

To study the influence of radomes in more detail, an additional solution was computed which is identical to solution $\mathrm{D}$, but neglects the radome calibrations. The largest differences with up to $\pm 10 \mathrm{~mm}$ occur in the height component. The horizontal component also changes by up to $\pm 8 \mathrm{~mm}$ for some stations. Stations equipped with the Trimble antenna TRM29659.00 and the UNAVCO radome UNAV show differences of about $5 \mathrm{~mm}$ in the north component and 6 to $8 \mathrm{~mm}$ in the east component. A part of these changes is caused by deficiencies in the calibration procedure for the antenna with radome: whereas for the antenna without radome a robot calibration including zenith- and azimuthdependent corrections is available, the values for the antenna with radome are converted from relative field calibration results including zenith-dependent corrections only. The neglect of the azimuth-dependence of the PCVs in combination with the effect of the radome are the reasons for the significant horizontal as well as vertical (about $10 \mathrm{~mm}$ ) displacement of the stations using this antenna. 

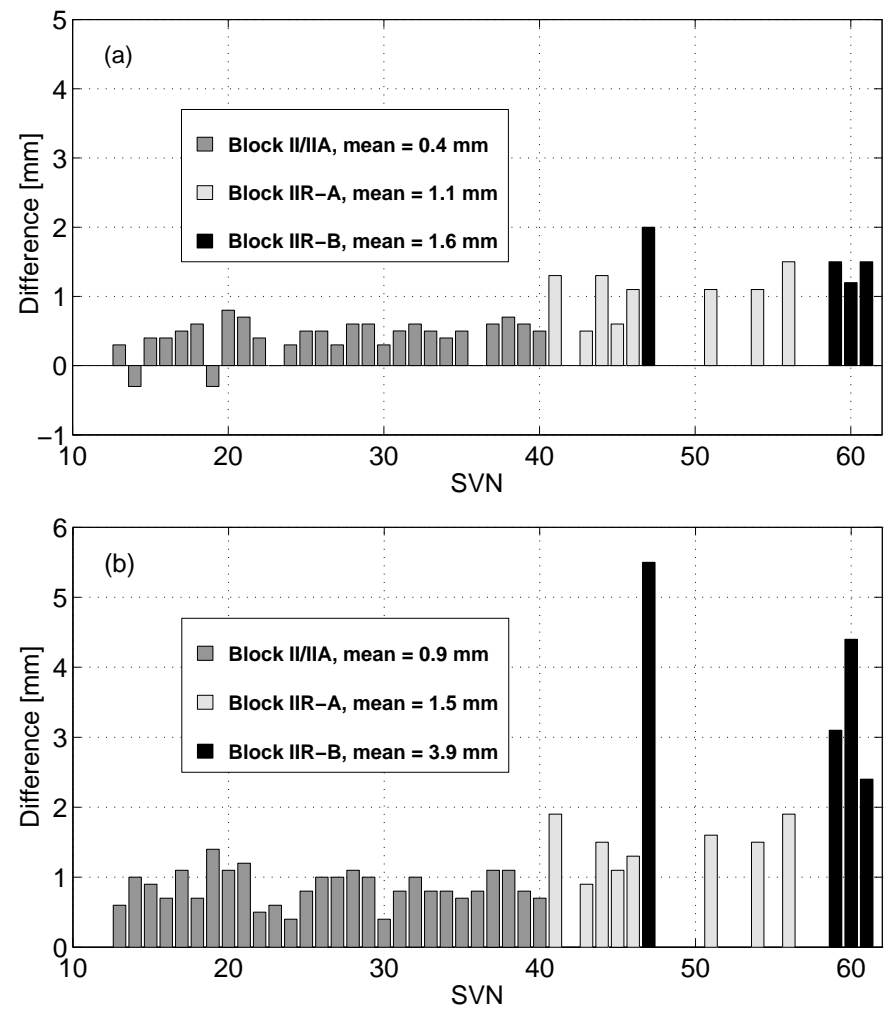

Fig. 16 RMS reduction of 3-day orbit fits through three 1-day orbital arcs: (a) relative PCVs (solution A) versus absolute PCVs with block-specific $z$-offsets (solution B), (b) relative PCVs (solution A) versus absolute PCVs with satellite-specific $z$-offsets (solution D). Due to their small number of observations, Block I satellites were excluded.

For the Ashtech antenna ASH700936C_M with SNOW radome both calibrations (with and without radome) are available with zenith- and azimuth-dependent corrections. As stations using this antenna show a shift of about $5 \mathrm{~mm}$ in the east component, one can conclude that the SNOW radome has a significant azimuth-dependent influence. As the number of calibrated antenna/radome combinations in our network is small (calibration available for only 20 out of 92 radome stations), the mean coordinate changes are rather small: $0.25 \mathrm{~mm}$ for the north, $-0.04 \mathrm{~mm}$ for the east and $0.68 \mathrm{~mm}$ for the up component.

\section{Outlook}

For the definition of the GPS satellite antenna parameters within the new absolute IGS antenna model named igs05_wwww . atx (available at ftp://igscb.jpl.nasa.gov/igscb/station/general/), the results from GFZ and TUM were taken to form the mean values the new model is based upon. Both ACs, together with other IGS ACs, will monitor the satellite antenna models on a regular basis. As soon as significant changes will be detected, an update of the IGS antenna model will be considered.

Especially important is the determination of antenna parameters for newly launched satellites. Their estimated antenna parameters over a few days or weeks will be tested against already existing ones. If its PCVs fit to one of the existing groups, only a $z$-offset will be derived based on the blockspecific PCV values. Otherwise, a new group will have to be defined. Until the release of new official values, the users have to apply block mean values.

This paper only describes the generation of the antenna models for the GPS satellites. In the meantime the Center for Orbit Determination in Europe (CODE) reprocessed about 15 months of data to derive consistent corrections for the GLONASS (and GPS) satellites on the basis of a combined GPS/GLONASS analysis (Schmid 2006). Since the absolute antenna model consisted of correction 

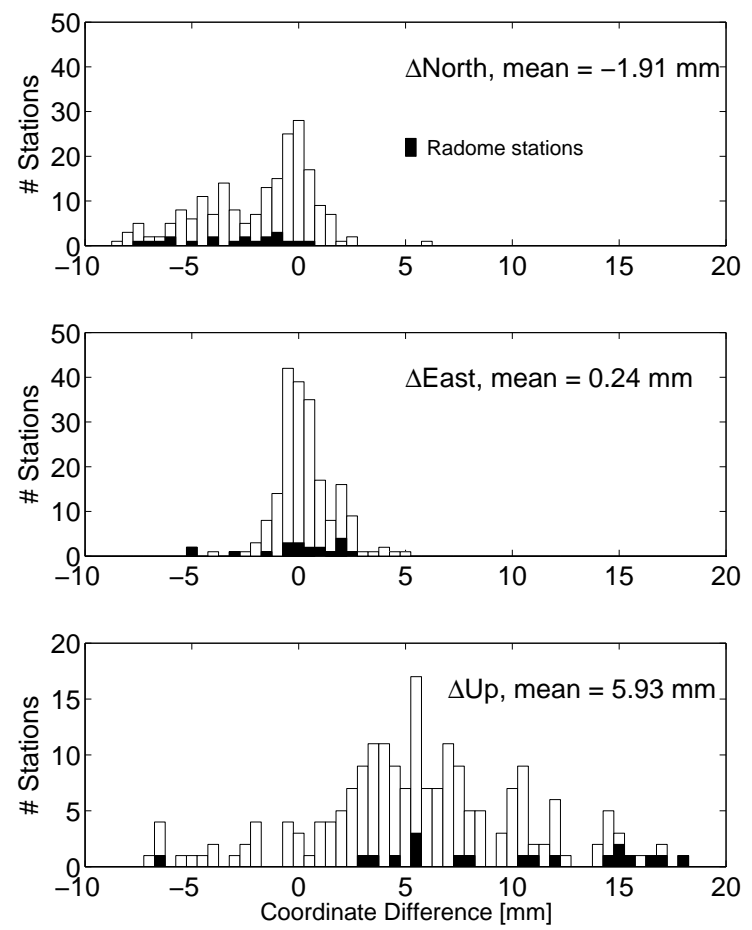

Fig. 17 Histograms of the mean coordinate changes between the solutions with relative (solution A) and absolute PCVs (solution D). Geocenter differences were removed by a 3-parameter similarity transformation.

values for all active GNSS satellites, it was ready for the adoption as the new standard by the IGS. A similar procedure will be necessary for the upcoming Galileo system. Even if the Galileo provider will calibrate the satellite antennas before launch, experience with GPS has shown that those values have to be confirmed by in-orbit analysis results and possibly adapted to the estimated models.

Furthermore, it is desirable that azimuth-dependent satellite antenna PCVs are analyzed in more detail together with the corresponding $x$ - and $y$-offsets. The single elements each GPS satellite antenna consists of can clearly be identified depending on the azimuthal direction (Schmid et al. 2005b). If additional ACs would generate such results, they could be combined with the JPL maps (Haines et al. 2004) in order to get a new IGS standard. First investigations have shown that station coordinates may be changed by $1-2 \mathrm{~mm}$ in global solutions and that the quality of GPS orbits could be improved by about half a mm, if azimuthal PCVs were considered.

As the latter numbers are rather small, there seems to be more need for action on the part of the receiver antenna. On the one hand, of course, each new antenna type has to be calibrated before use within the IGS network, but on the other hand there are also a lot of combinations of antenna and radome pairs in use that were not calibrated until now. In these cases, the calibration for the antenna without a radome is used. The conversion of relative field calibrations (see Sect. 2.1) that are limited to elevation dependence and that cannot provide PCVs below $10^{\circ}$ elevation is another suboptimal, temporary solution. That means that there is still a big demand for receiver antenna calibrations, also for antennas that are removed from reference frame stations to allow for an improved reprocessing. All future calibrations should be performed in an absolute way in order to get full models, either by the calibration robot from Hannover (Menge 2003) or, maybe, by an automated chamber calibration the University of Bonn is working on (Görres et al. 2006). The best would be, however, to avoid radomes wherever possible and to reduce the number of different antenna types within the IGS network.

The IGS switched to the new absolute antenna phase center model simultaneously with the switch to an IGS realization of the new international terrestrial reference frame ITRF2005 (http://itrf .ensg. ign.fr/; Altamimi et al. 2007) on 5 November 2006 (Gendt 2006). As a consequence, a discontinuity had to be observed in all IGS product time series. However, this discontinuity will be rectified by the 
complete reanalysis of all historic GPS data planned within the IGS (Steigenberger et al. 2007). In any case, users should avoid mixing results from solutions using different phase center conventions. Needless to say that the four constituents of the model, namely the PCOs and the PCVs for the receiver as well as the satellite antennas, should only be used consistently.

Acknowledgements We thank Dr. V. Tesmer (DGFI) for the analysis of the VLBI data, Dr. J. Boehm (Vienna University of Technology) for providing the ECMWF z200 data and Dr. G. Wübbena (Geo++ GmbH) and his group for the kindness to make the absolute robot calibration results available to the IGS. The TUM/DUT GPS reprocessing project was funded by the Deutsche Forschungsgemeinschaft (German Research Foundation).

\section{References}

Altamimi Z, Sillard P, Boucher C (2002) ITRF2000: A new release of the International Terrestrial Reference Frame for Earth science applications. J Geophys Res 107(B10), 2214, DOI: 10.1029/2001JB000561

Altamimi Z, Collilieux X, Legrand J, Garayt B, Boucher C (2007) ITRF2005: A new release of the International Terrestrial Reference Frame based on time series of station positions and Earth orientation parameters. J Geophys Res, submitted

Bar-Sever Y (1995) A new model for GPS yaw attitude. In: Gendt G, Dick G (eds) Proc IGS Workshop, Potsdam, May 1995, pp 128-140

Berg H (1948) Allgemeine Meteorologie - Einführung in die Physik der Atmosphäre. Ferdinand Dümmlers Verlag, Bonn

Beutler G, Brockmann E, Gurtner W, Hugentobler U, Mervart L, Rothacher M (1994) Extended orbit modeling techniques at the CODE Processing Center of the International GPS Service (IGS): Theory and initial results. Manuscr Geod 19(6): 367-386

Boehm J, Werl B, Schuh H (2006) Troposphere mapping functions for GPS and very long baseline interferometry from European Centre for Medium-Range Weather Forecasts operational analysis data. J Geophys Res 111(B2), B02406, DOI: 10.1029/2005JB003629

Braun J, Stephens B, Ruud O, Meertens C (1997) The effect of antenna covers on GPS baseline solutions. UNAVCO report, University NAVSTAR Consortium, Boulder (available at http://facility. unavco.org/ science_tech/dev_test/publications/dome_report/domeX5Freport-1.html)

Czopek FM, Shollenberger S (1993) Description and performance of the GPS Block I and II L-Band antenna and link budget. Proc ION-GPS93, The Institute of Navigation, Salt Lake City, September 1993, pp 37-43

Dach R, Hugentobler U, Fridez P, Meindl M (2007) Bernese GPS Software Version 5.0. Astronomical Institute, University of Bern

Dow JM, Neilan RE, Gendt G (2005) The International GPS Service (IGS): Celebrating the 10th anniversary and looking to the next decade. Adv Space Res 36(3): 320-326 DOI: 10.1016/j.asr.2005.05.125

Ferland R (2003) IGS00(v2) final. IGSMAIL-4666, IGS Central Bureau, Pasadena

Fritsche M, Dietrich R, Knöfel C, Rülke A, Vey S, Rothacher M, Steigenberger P (2005) Impact of higher-order ionospheric terms on GPS estimates. Geophys Res Lett 32(23), L23311, DOI: 10.1029/2005GL024342

Ge M, Gendt G (2005a) Estimation and validation of IGS absolute antenna phase center variations. In: Meindl M (ed) Proc IGS Workshop and Symposium, Bern, March 2004

Ge M, Gendt G, Dick G, Zhang FP, Reigber C (2005b) Impact of GPS satellite antenna offsets on scale changes in global network solutions. Geophys Res Lett 32(6), L06310, DOI: 10.1029/2004GL022224

Ge M, Gendt G, Dick G, Zhang FP (2005c) Improving carrier-phase ambiguity resolution in global GPS network solutions. J Geod 79(1-3): 103-110 DOI: 10.1007/s00190-005-0447-0

Gendt G, Dick G, Söhne W (1999) GFZ Analysis Center of IGS - Annual Report 1998. In: Gowey K, Neilan R, Moore A (eds) IGS 1998 Technical Reports, IGS Central Bureau, Pasadena, pp 79-87

Gendt G (2006) IGS switch to absolute antenna model and ITRF2005. IGSMAIL-5438, IGS Central Bureau, Pasadena

Görres B, Campbell J, Becker M, Siemes M (2006) Absolute calibration of GPS antennas: laboratory results and comparison with field and robot techniques. GPS Sol 10(2): 136-145 DOI: 10.1007/s10291-005-0015-3

Haines B, Bar-Sever Y, Bertiger W, Desai S, Willis P (2004) One-centimeter orbit determination for Jason-1: new GPS-based strategies. Marine Geodesy 27(1-2): 299-318 DOI: 10.1080/01490410490465300

Hefty J, Rothacher M, Springer T, Weber R, Beutler G (2000) Analysis of the first year of Earth rotation parameters with a sub-daily resolution gained at the CODE processing center of the IGS. J Geod 74(6): 479-487 DOI: $10.1007 / \mathrm{s} 001900000108$

Hugentobler U, Ineichen D, Beutler G (2003) GPS satellites: radiation pressure, attitude and resonance. Adv Space Res 31(8): 1917-1926 DOI: 10.1016/S0273-1177(03)00174-1

Kouba J (2003) A guide to using International GPS Service (IGS) products. IGS Central Bureau, Pasadena (available at http://igscb.jpl.nasa.gov/igscb/resource/pubs/GuidetoUsingIGSProducts.pdf)

Luzum BJ, Ray JR, Carter MS, Josties FJ (2001) Recent improvements to IERS Bulletin A combination and prediction. GPS Sol 4(3): 34-40 DOI: 10.1007/PL00012853

Mader GL (1999) GPS antenna calibration at the National Geodetic Survey. GPS Sol 3(1): 50-58 DOI: $10.1007 /$ PL00012780

Mader GL, Czopek FM (2002) The Block IIA satellite - Calibrating antenna phase centers. GPS World 13(5): $40-46$ 
Marquis W, Reigh D (2005) On-orbit performance of the improved GPS Block IIR antenna panel. Proc IONGNSS05, Long Beach, September 2005, pp 2418-2426

Menge F, Seeber G, Voelksen C, Wuebbena G, Schmitz M (1998) Results of absolute field calibration of GPS antenna PCV. Proc ION-GPS98, Nashville, September 1998, pp 31-38

Menge F (2003) Zur Kalibrierung der Phasenzentrumsvariationen von GPS-Antennen für die hochpräzise Positionsbestimmung. Wissenschaftliche Arbeiten der Fachrichtung Vermessungswesen der Universität Hannover, 247

Montenbruck O, Gill E (2000) Satellite orbits: models, methods, applications. Springer, Berlin Heidelberg New York

Navstar GPS Joint Program Office (2004) Navstar GPS space segment/navigation user interfaces (IS-GPS-200, Revision D). Interface specification, El Segundo (available at http://gps.afspc.af .mil/gpsoc/gps_documentation.htm)

Niell A (1996) Global mapping functions for the atmosphere delay at radio wavelengths. J Geophys Res 101(B2): 3227-3246 DOI: 10.1029/95JB03048

Niell A (2000) Improved atmospheric mapping functions for VLBI and GPS. Earth Planets Space 52(10): 699-702

Ray J, Dong D, Altamimi Z (2004) IGS reference frames: status and future improvements. GPS Sol 8(4): 251-266 DOI: 10.1007/s10291-004-0110-x

Ray J, Altamimi Z (2005) Evaluation of co-location ties relating the VLBI and GPS reference frames. J Geod 79(4-5): 189-195 DOI: 10.1007/s00190-005-0456-z

Ray J, Crump D, Chin M (2007) New global positioning system reference station in Brazil. GPS Sol 11(1): 1-10 DOI: $10.1007 / \mathrm{s} 10291-006-0032-\mathrm{x}$

Rothacher M (2001) Comparison of absolute and relative antenna phase center variations. GPS Sol 4(4): 55-60 DOI: $10.1007 /$ PL00012867

Rothacher M, Mader G (2003) Receiver and satellite antenna phase center offsets and variations. In: Tetreault P, Neilan R, Gowey K (eds) Proc IGS Network, Data and Analysis Centre Workshop, Ottawa, April 2002, pp 141-152

Saastamoinen J (1973) Contributions to the theory of atmospheric refraction. Bull Géod 107: 13-34 DOI: $10.1007 / \mathrm{BF} 02522083$

Saha S, Nadiga S, Thiaw C, Wang J, Wang W, Zhang Q, Van den Dool HM, Pan H-L, Moorthi S, Behringer D, Stokes D, Peña M, Lord S, White G, Ebisuzaki W, Peng P, Xie P (2006) The NCEP climate forecast system. J Clim 19(15): 3483-3517 DOI: 10.1175/JCLI3812.1

Schmid R, Rothacher M (2003) Estimation of elevation-dependent satellite antenna phase center variations of GPS satellites. J Geod 77(7-8): 440-446 DOI: 10.1007/s00190-003-0339-0

Schmid R, Mader G, Herring T (2005a) From relative to absolute antenna phase center corrections. In: Meindl M (ed) Proc IGS Workshop and Symposium, Bern, March 2004, pp 209-219

Schmid R, Rothacher M, Thaller D, Steigenberger P (2005b) Absolute phase center corrections of satellite and receiver antennas: Impact on global GPS solutions and estimation of azimuthal phase center variations of the satellite antenna. GPS Sol 9(4): 283-293 DOI: 10.1007/s10291-005-0134-x

Schmid R (2006) igs05_1390.atx - New release of the absolute IGS antenna correction file. IGSMAIL-5400, IGS Central Bureau, Pasadena

Schöne T (2004) TIGA - Tide gauge benchmark monitoring pilot project. In: Gowey K, Neilan R, Moore A (eds) IGS 2001-2002 Technical Reports, IGS Central Bureau, Pasadena, pp 225-230

Schupler BR, Allshouse RL, Clark TA (1994) Signal characteristics of GPS user antennas. J Inst Navigation 41: $277-295$

Springer TA (2000a) Modeling and validating orbits and clocks using the global positioning system. Geodätischgeophysikalische Arbeiten in der Schweiz, 60, Swiss Geodetic Commission

Springer TA (2000b) Common interests of the IGS and the IVS. In: Vandenberg NR, Baver KD (eds) Proc IVS General Meeting, Kötzting, February 2000, pp 296-305

Steigenberger P, Rothacher M, Dietrich R, Fritsche M, Rülke A, Vey S (2006) Reprocessing of a global GPS network. J Geophys Res 111(B5), B05402, DOI: 10.1029/2005JB003747

Steigenberger P, Romero I, Fang P' (2007) Reprocessing issues, standardization, new models. In: Proc IGS Workshop, Darmstadt, May 2006, in press

Tesmer V, Kutterer H, Drewes H (2004) Simultaneous estimation of a TRF, the EOP and a CRF. In: Vandenberg NR, Baver KD (eds) Proc IVS General Meeting, Ottawa, February 2004, pp 311-314

Thaller D, Dill R, Krügel M, Steigenberger P, Rothacher M, Tesmer V (2006) CONT02 analysis and combination of long EOP series. In: Flury J, Rummel R, Reigber Ch, Rothacher M, Boedecker G, Schreiber U (eds) Observation of the Earth system from space, Springer, Berlin Heidelberg New York, pp 389-411

Thomas CC, MacMillan DS (2003) CORE operation center report. In: Vandenberg NR, Baver KD (eds) IVS 2002 Annual Report, NASA/TP-2003-211619, Goddard Space Flight Center, Greenbelt

Zhang FP, Gendt G, Wuensch J, Ge M, van Dam T (2005) Impact of atmospheric pressure loading on the stability of reference frame and vertical motion rate derived by GPS. Geophys Res Abstr 7, 01077

Zhu SY, Massmann F-H, Yu Y, Reigber C (2003) Satellite antenna phase center offsets and scale errors in GPS solutions. J Geod 76: 668-672 DOI: 10.1007/s00190-002-0294-1 